\title{
BDNF in Lower Brain Parts Modifies Auditory Fiber Activity to Gain Fidelity but Increases the Risk for Generation of Central Noise After Injury
}

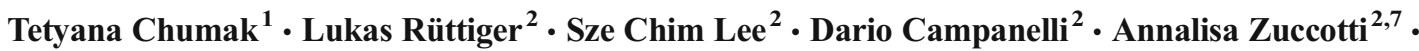 \\ Wibke Singer $^{2}$ - Jiří Popelár ${ }^{1} \cdot$ Katja Gutsche $^{3} \cdot$ Hyun-Soon Geisler ${ }^{2}$ - Sebastian Philipp Schraven ${ }^{4}$. \\ Mirko Jaumann ${ }^{2}$ - Rama Panford-Walsh ${ }^{5}$ • Jing Hu ${ }^{6}$. Thomas Schimmang ${ }^{3}$. \\ Ulrike Zimmermann $^{2} \cdot$ Josef Syka $^{1}$ - Marlies Knipper ${ }^{2}$
}

Received: 30 April 2015 / Accepted: 5 October 2015 /Published online: 17 October 2015

(C) The Author(s) 2015. This article is published with open access at Springerlink.com

\begin{abstract}
For all sensory organs, the establishment of spatial and temporal cortical resolution is assumed to be initiated by the first sensory experience and a BDNF-dependent increase in intracortical inhibition. To address the potential of cortical BDNF for sound processing, we used mice with a conditional deletion of BDNF in which Cre expression was under the control of the Pax 2 or TrkC promoter. BDNF deletion profiles between these

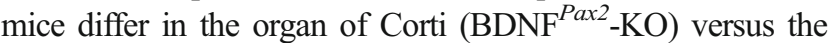
auditory cortex and hippocampus (BDNF $\left.{ }^{\text {TrkC }}-\mathrm{KO}\right)$. We demonstrate that $\mathrm{BDNF}^{\text {Pax2 }}-\mathrm{KO}$ but not $\mathrm{BDNF}^{\text {TrkC }}-\mathrm{KO}$ mice exhibit reduced sound-evoked suprathreshold $\mathrm{ABR}$ waves at the level of the auditory nerve (wave I) and inferior colliculus (IC) (wave IV), indicating that BDNF in lower brain regions but not in the auditory cortex improves sound sensitivity during hearing onset. Extracellular recording of IC neurons of $\mathrm{BDNF}^{\text {Pax2 }}$ mutant mice revealed that the reduced sensitivity of auditory fibers in these mice went hand in hand with elevated thresholds, reduced dynamic range,
\end{abstract}

Tetyana Chumak and Lukas Rüttiger contributed equally to this work.

Marlies Knipper

marlies.knipper@uni-tuebingen.de

1 Department of Auditory Neuroscience, Institute of Experimental Medicine, Academy of Sciences of the Czech Republic, Vídeňská 1083, 14220 Prague, Czech Republic

2 Department of Otolaryngology, Hearing Research Centre Tübingen, Molecular Physiology of Hearing, University of Tübingen, Elfriede-Aulhorn-Str. 5, 72076 Tübingen, Germany

3 Instituto de Biologíay Genética Molecular, Universidad de Valladolid y Consejo Superior de Investigaciones Científicas, E-47003 Valladolid, Spain prolonged latency, and increased inhibitory strength in IC neurons. Reduced parvalbumin-positive contacts were found in the ascending auditory circuit, including the auditory cortex and hippocampus of $\mathrm{BDNF}^{\text {Pax } 2}-\mathrm{KO}$, but not of $\mathrm{BDNF}^{\text {TrkC }}-\mathrm{KO}$ mice. Also, $\mathrm{BDNF}^{\text {Pax } 2}-\mathrm{WT}$ but not $\mathrm{BDNF}^{\text {Pax2 }}-\mathrm{KO}$ mice did lose basal inhibitory strength in IC neurons after acoustic trauma. These findings suggest that BDNF in the lower parts of the auditory system drives auditory fidelity along the entire ascending pathway up to the cortex by increasing inhibitory strength in behaviorally relevant frequency regions. Fidelity and inhibitory strength can be lost following auditory nerve injury leading to diminished sensory outcome and increased central noise.

Keywords BDNF · Central hyperactivity $\cdot$ High-spontaneous rate, low-threshold fibers $\cdot$ Homeostatic plasticity $\cdot$ Inferior colliculus $\cdot$ Sound detection threshold
4 Department of Otolaryngology, Plastic, Aesthetic and Reconstructive Head and Neck Surgery, Comprehensive Hearing Center, University of Würzburg, Josef-Schneider-Straße 11, 97080 Würzburg, Germany

5 DNA Genotek Inc., 2 Beaverbrook Road, Kanata, ON K2K 1L1, Canada

6 Centre for Integrative Neuroscience, University of Tübingen, Otfried-Müller-Straße 25, 72076 Tübingen, Germany

7 Department of Clinical Neurobiology, University Hospital and DKFZ Heidelberg, In Neuenheimer Feld 280, 69120 Heidelberg, Germany 


\begin{tabular}{ll} 
Abbreviations \\
ABR & Auditory brainstem response \\
AC & Auditory cortex \\
Arc & Activity-regulated cytoskeletal protein \\
AT & Acoustic trauma \\
BBN & Broadband noise \\
BDNF & Brain-derived nerve growth factor \\
CF & Characteristic frequency \\
CN & Cochlear nucleus \\
DCN & Dorsal cochlear nucleus \\
DPOAE & Distortion product of the otoacoustic emission \\
IC & Inferior colliculus \\
IHC & Inner hair cell \\
KO & Knockout \\
mFSL & Minimum first-spike latency \\
OHC & Outer hair cells \\
PV & Parvalbumin \\
RIF & Rate-intensity function \\
ROSA26R & ROSA26 reporter mouse \\
SGN & Spiral ganglion neuron \\
SPL & Sound pressure level \\
VCN & Ventral cochlear nucleus \\
WT & Wild type \\
$\beta$-gal & $\beta$-Galactosidase \\
\hline
\end{tabular}

\section{Introduction}

Brain-derived neurotrophic factor (BDNF) was initially identified as a survival factor for peripheral neurons (reviewed in $[1,2])$. Increasing evidence is now emerging that BDNF acts locally as a factor that governs dendritogenesis and the spine phenotype [3-6] at certain stages of maturation [7]. Upon sensory experience in the auditory [8,9], visual [10], somatosensory [11], and olfactory system [12], the dendritic complexity of parvalbumin (PV)-immunoreactive interneurons is particularly enhanced in response to increases in local cortical $\operatorname{BDNF}[4,8,11]$. This process is assumed to enhance sensory resolution and acuity, and requires an adequate and timely sensory input [13-15]. The selective role of cortical BDNF for improvement of sensory resolution was questioned in the retina where BDNF was proposed as a mediator of early environmental enrichment effects on visual acuity [16]. Accordingly, blocking retinal BDNF by means of antisense oligonucleotides prior to eye opening was shown to prevent the effects on dendritic segregation of retinal ganglion cells [17] and development of retinal acuity [16] upon exposure to environmental enrichment. As constitutive BDNF knockout (KO) mice $[18,19]$ die too prematurely to assess the role of BDNF in the mature sensory organs, the role of peripheral versus central BDNF for sensory resolution and acuity is still obscure. Until now, it also remains unclear if and how these crucial effects of BDNF during the development of normal sensory function are linked to the complex changes of BDNF activity in mature systems, which have been described as either adaptive responses to injury [20] or nonadaptive responses in various brain disorders [21].

In rodent auditory systems, BDNF is downregulated in hair cells of the cochlea from birth onwards but remains expressed in the inner border and phalangeal cells that ensheath inner hair cells (IHCs) [22] and is upregulated with hearing onset in spiral ganglion neurons (SGNs) at the level of higher frequency cochlear turns (for a review, see [15]). While loss of BDNF in phalangeal cells does not affect hearing [23], the combined deletion of BDNF in the cochlea, the dorsal cochlear nucleus (DCN), and the inferior colliculus (IC) in $\mathrm{BDNF}^{P a x 2}$ - $\mathrm{KO}$ mice $[24,25]$ leads to reduced exocytosis of otherwise mature IHC synapses and to slightly diminished sound-induced auditory brainstem responses [25]. This finding suggested an unexpected role of BDNF in the lower parts of the auditory pathway for hearing sensitivity upon sensory experience. To obtain more insight into such a role of BDNF on basic sound processing, we compared sound sensitivity and noise vulnerability of $\mathrm{BDNF}^{\text {Pax } 2}-\mathrm{KO}$ mice with that of mice in which BDNF is deleted more widespread throughout the auditory system including the auditory cortex using a mouse line in which Cre is driven by the TrkC promoter [26]. Strikingly, reduced sound sensitivity occurs only in $\mathrm{BDNF}^{\text {Pax2 }}$-KO mice but not in $\mathrm{BDNF}^{T r k C}-\mathrm{KO}$ mice. This differential response is observed although both strains exhibit a similar BDNF deletion profile in the SGNs of the cochlea and in the IC, the midbrain integration center of the ascending auditory pathway [27, 28] [present study]. Results from recordings of extracellular sound-evoked responses from IC neurons in $\mathrm{BDNF}^{\text {Pax } 2}$ wild-type (WT) and $\mathrm{BDNF}^{\text {Pax } 2}$-KO mice and measurements of the density of inhibitory marker proteins along the auditory pathway and hippocampus suggest that BDNF in the lower parts of the auditory CNS or within the cochlea triggers basal PV inhibitory circuits to increase auditory fidelity upon sensory experience. However, this early improvement of sensitivity is accompanied by the risk to lose sensitivity and generate elevated noise levels when the BDNF-modified driving force is deteriorated after peripheral auditory nerve injury in the mature auditory system.

\section{Materials and Methods}

\section{Animals}

$\mathrm{BDNF}^{\text {Pax2 }}$-KO mice were obtained by mating Pax2-Cre [24] with $\mathrm{BDNF}^{\text {lox } / o x}$ mice [29]. $\mathrm{BDNF}^{T{ }^{T k C}}$-KO mice were generated by mating TrkC-Cre [26] with $\mathrm{BDNF}^{\text {lox/lox }}$ mice. $\mathrm{BDNF}^{\text {Pax } 2}-\mathrm{KO}$ mice had a deletion of BDNF in the cochlea, $\mathrm{DCN}$, and IC [25]. In BDNF ${ }^{T r k C}-\mathrm{KO}$ mice, BDNF was conditionally inactivated in neurons. TrkC-Cre mice and Pax2- 
Cre mice were crossed with ROSA26 reporter (ROSA26R) mice as described [25]. For detection of $\beta$-galactosidase activity in the Pax2-Cre-ROSA26R or TrkC-Cre-ROSA26R mouse line, adult mice were used. $\beta$-Galactosidase activity was analyzed through $\mathrm{X}$-gal staining and immunohistochemistry with anti- $\beta$-galactosidase antibody as described below. Deletion of the BDNF gene in distinct brain areas of $\mathrm{BDNF}^{\text {Pax2 }}-\mathrm{KO}$ and $\mathrm{BDNF}^{\text {TrkC }}-\mathrm{KO}$ mice was verified by Northern and Western blots. Control and knockout mice of either sex were used for the experiments.

The care and use of animals was approved by either the University of Tübingen, Veterinary Care Unit and the Animal Care and Ethics Committee of the regional board of the Federal State Government of Baden-Württemberg, Germany, or by the Ethics Committee of the Institute of Experimental Medicine, Academy of Sciences of the Czech Republic, and followed the guidelines of the EU Directive 2010/63/EU for animal experiments.

\section{Tissue Preparation, X-gal Staining, Immunohistochemistry, and Ribbon Counts}

Cochlear and brain tissues were isolated and dissected as previously described [30]. Briefly, cochleae and brains were fixed in $100 \mathrm{mM}$ phosphate-buffered saline (PBS) containing $2 \%$ paraformaldehyde and $125 \mathrm{mM}$ sucrose, $\mathrm{pH} \mathrm{7.4,} \mathrm{for} 2$ and $48 \mathrm{~h}$, respectively. Cochleae were decalcified in Rapid Bone Decalcifier (Eurobio, Les Ulis Cedex, France) followed by an overnight incubation in $25 \%$ sucrose in Hanks' buffered saline (HBS). Cochleae were embedded in O.C.T. compound (Miles Laboratories, Elkhart, IN, USA). Tissue samples were cryosectioned at $10 \mu \mathrm{m}$ thickness for immunohistochemistry, mounted on Super-Frost*/plus microscope slides, and stored at $-20{ }^{\circ} \mathrm{C}$ [31]. Brains were embedded after fixation in $4 \%$ agarose, cut at $60 \mu \mathrm{m}$ thickness with a Vibratome (Leica VT 1000S, Wetzlar, Germany), and stored in PBS at $4{ }^{\circ} \mathrm{C}$. Brain regions were identified in accordance with the mouse atlas of Franklin and Paxinos [32]. Serial sections derived from coronal brain slices between 1.8 and $2.3 \mathrm{~mm}$ posterior to bregma were analyzed. For cochlear whole-mount preparations, the temporal bone was dissected on ice and immediately fixed for $2 \mathrm{~h}$ using $2 \%$ paraformaldehyde in $100 \mathrm{mM}$ PBS by infusion through the round and oval window. Cochlear turns were dissected and transferred to slides and attached to the surface using Cell-Tak (BD Bioscience, Heidelberg, Germany).

For X-gal staining, brain slices and isolated cochleae, slit from the apex to base, were incubated with the $\beta$-galactosidase staining solution containing $0.5 \mathrm{mg} / \mathrm{ml} \mathrm{X}$-gal (Sigma), $5 \mathrm{mM} \mathrm{K}_{3}\left[\mathrm{Fe}(\mathrm{CN})_{6}\right]$, and $5 \mathrm{mM} \mathrm{K}_{4}\left[\mathrm{Fe}(\mathrm{CN})_{6}\right]$ in PBS complemented with $20 \mathrm{mM} \mathrm{MgCl}_{2}, 0.01 \%$ sodium deoxycholate, and $0.02 \%$ Nonidet-P40 overnight at $37{ }^{\circ} \mathrm{C}$. After incubation with $\beta$-galactosidase staining solution, whole-mount preparations of the cochleae were performed.
In case of a successful deletion of the floxed ROSA26R locus, the presence of $\beta$-galactosidase protein is visualized with the enzyme's substrate (X-gal), resulting in a blue precipitate only in cells expressing $\mathrm{Cre}$ recombinase.

Immunohistochemistry was performed as described before $[33,34]$. Briefly, after washing and permeabilization, tissue slices were incubated overnight with primary antibody at $4{ }^{\circ} \mathrm{C}$. For double labeling studies, specimens were simultaneously incubated with both antibodies. Primary antibodies were detected with $\mathrm{Cy} 3$-conjugated (Jackson ImmunoResearch) and AlexaFluor 488-conjugated secondary antibodies (Life Technologies GmbH, Darmstadt, Germany). Slices were mounted with Vectashield mounting medium containing DAPI (Vector laboratories, Burlingame, CA, USA). Sections and wholemount preparations were viewed using an Olympus BX61 microscope equipped with epifluorescence illumination.

For ribbon counting, image acquisition and CtBP2/ RIBEYE-immunopositive spot counting were carried out as previously described [33]. Briefly, cryosectioned cochleae were imaged over a distance of $8 \mu \mathrm{m}$ covering the entire IHC nucleus and beyond in an image-stack along the $z$-axis (z-stack). One z-stack consisted of about 16 layers with a $z$ increment of $0.49 \mu \mathrm{m}$; for each layer, one image per fluorochrome was acquired. To assess spatial protein distribution, $z$ stacks were three-dimensionally deconvoluted using the cellSens constrained iterative module with the Advanced Maximum Likelihood Estimation (ADMLE) algorithm (OSIS $\mathrm{GmbH}$ ), Voxel Viewer, and Slice Viewer (cellSens, OSIS $\mathrm{GmbH})$.

Antibodies The following antibodies were used: mouse anti- $\beta$-galactosidase (Promega, Mannheim, Germany), mouse anti-parvalbumin, rabbit anti-SK2 (Sigma-Aldrich, Munich, Germany), rabbit anti-GFAP (Dako, Glostrup, Denmark), rabbit anti-parvalbumin, mouse anti-GAD67 (Merck Millipore, Darmstadt, Germany), rabbit anti-Arc, rabbit anti-VGLUT2, rabbit anti-MAP2 [35] (Synaptic Systems, Göttingen, Germany), rabbit anti-Ibal (Wako Chemicals GmbH, Neuss, Germany), rabbit anti-BDNF (Santa Cruz Biotechnology, Heidelberg, Germany), rabbit anti-BK (Alomone Labs, Jerusalem, Israel), rabbit anti-CtBP2/RIBEYE (Cell Applications, San Diego, CA, USA), and rabbit anti-KCNQ4 [36].

Image Analysis The acquired images were analyzed using the free software Image $(\mathrm{NIH}$, Bethesda, MD, USA) to evaluate the expression of parvalbumin and GAD67. In every picture, the background was reduced with the rolling ball algorithm, and therefore, the red, green, and blue channels have been separated. In the green channel (parvalbumin or GAD67), a threshold (with ImageJ standard parameters) has been applied and therefore the ImageJ built-in plugin, Analyze Particles, has been used to count the numbers of parvalbumin or GAD67 puncta. 


\section{Northern Blots}

Riboprobes were designed as described in [30]. Messenger RNA (mRNA) isolation was performed using the Oligotex mRNA Direct Mini Kit (Qiagen, Germany). mRNA was loaded onto a denaturing $0.8 \%$ agarose formaldehyde gel and transferred onto a nylon membrane (Roche, Germany). The membrane was blocked and hybridized overnight at $65{ }^{\circ} \mathrm{C}$ with riboprobes for BDNF, Arg3.1, and cyclophilin. The membrane was incubated with anti-Dig-AP (Roche; 1:20, 000). mRNA was detected with CDP-Star ready to use (Roche) and exposed to X-ray films.

\section{Western Blots}

Proteins were extracted using the NucleoSpin RNA/protein kit (Macherey-Nagel, Germany) following the manufacturer's instructions. SDS-PAGE and Western blotting were carried out using the "XCell II SureLock ${ }^{\mathrm{TM}}$ Mini-Cell and XCell II Blot Module" (Invitrogen, Germany) as previously described [37]. The blotted proteins were incubated with either rabbit polyclonal or mouse monoclonal antibodies for BDNF (Santa Cruz Biotechnology, Heidelberg, Germany), activity-regulated cytoskeletal protein (Arc) (Synaptic Systems, Göttingen, Germany), parvalbumin (Merck Millipore, Darmstadt, Germany), GAD67 (Merck Millipore, Darmstadt, Germany), or GAPDH (Abcam, Cambridge, UK).

\section{Noise Exposure}

For acoustic trauma (AT), animals were anesthetized (75 mg/kg ketamine hydrochloride, Ketavet, Pharmacia, Pfizer, Karlsruhe, Germany; $5 \mathrm{mg} / \mathrm{kg}$ xylazine hydrochloride, Rompun $2 \%$, Bayer Leverkusen, Germany; in injection water to give an application volume of $5 \mathrm{ml} / \mathrm{kg}$ body weight) and exposed to intense pure tone noise $(10 \mathrm{kHz}, 116 \mathrm{~dB}$ sound pressure level (SPL) for $40 \mathrm{~min}$ ) in a reverberating chamber, binaurally in an open field [25]. Control sham-exposed animals underwent the same procedure but with no traumatic sound presented (i.e., the speaker remained turned off).

\section{Hearing Function Evaluation}

Hearing thresholds were evaluated from auditory brainstem responses (ABRs). The state of outer hair cells (OHCs) in the organ of Corti was studied by recording otoacoustic emissions. The ABR to click and pure tone stimuli and the cubic $2 \times f 1-f 2$ distortion product of the otoacoustic emission (DPOAE) for $f 2=1.24 \times f 1$ and $\mathrm{L} 2=\mathrm{L} 1-10 \mathrm{~dB}$ were recorded in mice aged 6-9 weeks. All physiological recordings were performed under anesthesia (for details, see above) in a soundproof chamber (IAC, Niederkrüchten, Germany) as previously described [38].
Auditory Brainstem Responses ABRs, evoked by shortduration sound stimuli, represent the summed activity of neurons in distinct anatomical structures or nuclei along the ascending auditory pathway [39] and are measured by averaging the evoked electrical response recorded via subcutaneous electrodes. Briefly, ABRs were evoked by click $(100 \mu \mathrm{s})$ or pure tone stimuli ( $3 \mathrm{~ms}$ duration, $1 \mathrm{~ms}$ rise/fall times, frequencies $2-45.3 \mathrm{kHz}$ ) of gradually increasing sound pressure in $5 \mathrm{~dB}$ steps of intensity. The response threshold was determined at each frequency as the minimal sound pressure evoking a noticeable potential peak in the expected time window of the recorded signal. For details, see [38].

Distortion Product Otoacoustic Emissions We assessed $\mathrm{OHC}$ function by the growth function and the maximum response in the distortion product audiogram of the cubic DPOAE as described [34]. Frequency pairs of tones were between $f 2=4 \mathrm{kHz}$ and $f 2=32 \mathrm{kHz}$.

\section{ABR Wave Form Analysis}

ABR waveforms were analyzed for consecutive amplitude deflections (waves), with each wave consisting of a starting negative (n) peak and the following positive (p) peak. Peak amplitudes of ABR waves I and IV were extracted in the present study and defined as wave $I: I_{n}-I_{p}(0.9-2 \mathrm{~ms})$; wave $I V: \mathrm{IV}_{\mathrm{n}}-\mathrm{IV}_{\mathrm{p}}(3.4-5.9 \mathrm{~ms})$. A customized program was used to extract ABR peaks based on these definitions. ABR peak-topeak (wave amplitude) growth functions were constructed for individual ears based on the extracted peaks for increasing stimulus levels. All ABR wave amplitude growth functions were calculated for increasing stimulus levels with reference to the ABR thresholds (from -20 to a maximum of $75 \mathrm{~dB}$ above threshold before noise exposure and from -20 to a maximum of $55 \mathrm{~dB}$ above threshold after noise exposure). For illustrative purposes, ABR wave amplitude growth functions were first linearly interpolated to the resolution of 1 data point/dB and then smoothed by a moving zero-phase Gaussian filter with a window length of 9 data points $(9 \mathrm{~dB})$. The ABR waveforms shown in the inset of the figures were smoothed by a moving zero-phase Gaussian filter with a window length of 5 data points $(0.5 \mathrm{~ms})$.

\section{Extracellular Recording of the Neuronal Activity in the IC}

Four groups of animals were tested: control, wild-type (WTc, $n=4$ ), and knockout (KOc, $n=4)$ mice and mice with auditory trauma, WTat $(n=5)$ and KOat $(n=5)$. Mice with auditory trauma were exposed to noise at the age of 9-10 weeks and extracellular recordings were performed at 13-20 weeks. The surgery and extracellular recording in the IC were performed in mice anesthetized with $35 \mathrm{mg} / \mathrm{kg}$ ketamine (Narkamon $5 \%$; Spofa, Prague, Czech Republic) and $6 \mathrm{mg} / \mathrm{kg}$ xylazine 
(Sedazine $2 \%$; Fort Dodge, Animal Health, Fort Dodge, Iowa) in saline via intraperitoneal injection. Body temperature was maintained with a DC-powered electric temperatureregulated pad. Recordings were carried out in a soundproof anechoic room.

Surgical and Recording Procedures For access to the IC, an incision was made through the skin of the skull and underlying muscles were retracted to expose the dorsal cranium. A holder was glued to the skull. Small holes were drilled over both IC of the mouse; the animal was transported to the soundproof anechoic room and placed on a heating pad, which maintained a $37-38{ }^{\circ} \mathrm{C}$ body temperature. Neuronal activity in the IC was recorded using a 16-channel, single shank probe (NeuroNexus Technologies) with $100 \mu \mathrm{m}$ between the electrode spots or single parylene-coated tungsten electrode (Bionic Technologies Inc). The signal obtained from the electrode was amplified 10,000 times, band-pass filtered over the range of $300 \mathrm{~Hz}$ to $10 \mathrm{kHz}$, and processed by a TDT System III (Tucker Davis Technologies, Alachua, FL, USA) using an RX5-2 Pentusa Base Station. The recorded data was processed and analyzed with a custom software based on MATLAB.

Frequency-Intensity Mapping Using frequency-intensity mapping as described in [40], the tuning properties of individual IC neurons were evaluated. To determine the excitatory response area, pure tone bursts $(100 \mathrm{~ms}$ in duration, $5 \mathrm{~ms}$ rise/fall times) with variable frequency (1/8 octave step) and intensity ( $5 \mathrm{~dB}$ step) were presented in random order.

A two-dimensional matrix was thereby obtained, with elements corresponding to the response magnitudes in the respective frequency-intensity points. The discrete point matrix was then converted to a smooth function of two variables, frequency and intensity, a process involving cubic smoothing spline interpolation. This averaging method allowed us to overcome the limited resolution of the frequency-intensity map. The resulting smooth function thereafter served as a basis for the extraction of all the parameters of interest: (i) the excitatory response threshold, the lowest stimulus intensity that excited the neuron, measured in $\mathrm{dB}$ SPL; (ii) the characteristic frequency $(\mathrm{CF})$, the frequency with the minimal response threshold, measured in $\mathrm{kHz}$; and (iii) the bandwidth of the excitatory area $10 \mathrm{~dB}$ above the excitatory threshold, measured by quality factor $Q_{10}$. Quality factor $Q_{10}$ is a common measure of frequency selectivity that is reciprocally related to the excitatory area bandwidth (the higher the $Q_{10}$, the sharper the response), defined as $Q_{10}=\mathrm{CF} /$ bandwidth.

Two-Tone Stimulation To detect inhibitory areas, a two-tone stimulation was employed [40]. Two-tone inhibition in the IC consists of two components: intrinsic inhibition and suppression from lower auditory centers. Local inhibition is typically characterized by the effects of off-CF tones on spontaneous activity. Also the two-tone stimulation paradigm is commonly used to evaluate the local inhibition on the level of the cochlear nucleus (CN) [41-43], the IC [44, 45], and the auditory cortex (AC) [46]. Using the two-tone stimulation, the contribution of cochlear suppression cannot be excluded in the current study. However, we conclude that central inhibition on the level of the IC mainly contributes to the neural inhibition, since the shapes of the inhibitory areas in representative neurons stimulated with two-tone stimulation corresponded well with those obtained by inhibition of spontaneous activity. Pure tone at the neuron's $\mathrm{CF}$ fixed $10 \mathrm{~dB}$ above the threshold at $\mathrm{CF}$ and pure tone bursts of variable frequency and intensity, analogous to those used for the excitatory area mapping, were simultaneously presented. Similar to frequency-intensity mapping, a two-dimensional matrix was obtained. Spike rates of responses in noninhibited areas (outside the excitatory area), inhibited areas, and excited areas (20 dB above threshold) were determined. Inhibitory strength was calculated as the ratio of spike numbers per stimulus in inhibited areas to those in noninhibitory areas. Low- and high-frequency inhibition bands were analyzed separately. Neurons displaying inhibition with a strength of $20 \%$ and higher were considered to be neurons displaying inhibition, and their numbers were compared between groups. In addition to inhibitory strength, the ratio of response magnitude in excitatory to noninhibitory areas was evaluated.

Intensity Coding in the IC Neuronal responses to broadband noise (BBN) bursts of variable intensity (from 0 to $90 \mathrm{~dB}$ SPL, $10 \mathrm{~dB}$ steps, 50 repetitions) were used to construct the rateintensity function (RIF) from which response threshold, maximal response magnitude, dynamic range, and relative initial slope of the RIF were determined [47]. From the RIF, further response parameters such as spontaneous firing rate and firstspike latency were assessed. Spontaneous firing rate of each neuron was determined from poststimulus time histograms to BBN stimulation from 200-300 ms after presentation of the stimulus $10 \mathrm{~dB}$ above the threshold. Minimum first-spike latency (mFSL) was evaluated from the poststimulus time histograms to BBN stimuli at $80 \mathrm{~dB}$ SPL, as the amount of time between the onset of sound presentation and the appearance of first spikes of neuronal responses.

\section{Statistical Analysis}

Data are presented either as the mean \pm standard deviation (SD) or standard error of the mean (SEM) for values with normal distributions or the median $(\mathrm{Mdn})$ for values with nonnormal distributions. For statistical analysis, the GraphPad Prism software was used. To assess differences in mean or median values between groups, two-sided Student's $t$ tests, 
one-way or two-way ANOVA with Bonferroni's multiple comparison test, Kruskal-Wallis tests with Dunn's multiple comparison test, or chi-square tests were employed.

\section{Results}

\section{Differential Deletion of BDNF in the Cochlea and Brain in Pax2-Cre Versus TrkC-Cre Mouse Lines}

To define the source of BDNF that is responsible for the absence of normal hearing thresholds of $\mathrm{BDNF}^{\operatorname{Pax}^{2}-\mathrm{KO} \text { animals }}$ [25], we compared the auditory phenotype of BDNF-Pax2Cre transgenic mice with that of BDNF-TrkC-Cre mice, in which the Cre gene is controlled by the TrkC promoter [26]. A detailed comparative analysis of BDNF deletion patterns in the ascending auditory pathway was performed for both $\mathrm{Cre}$ mouse lines, using $X$-gal staining and anti- $\beta$-galactosidase $(\beta$ gal) immunolabeling (Fig. 1). X-gal staining confirmed intense labeling of hair cells and SGNs for Pax2-Cre-ROSA26R mice (Fig. 1a, upper panel), whereas for TrkC-Cre-ROSA26R mice, X-gal staining was observed mainly in SGNs but not in hair cells (Fig. 1b, upper panel). A similar result was observed when $\beta$-gal immunolabeling was used (Fig. 1a, b, lower panels). Negative controls showed no staining (Fig. 1a, b, inset).

At the level of the $\mathrm{CN}, \beta$-gal was detected exclusively in the DCN in the presence of the Pax2 promoter [25], whereas with the TrkC promoter, DCN and ventral cochlear nucleus (VCN) neurons were stained (not shown). In both Pax2-CreROSA26R and TrkC-Cre-ROSA26R mice, an intense and widespread staining for $\beta$-gal was observed at the level of the IC (Fig. 1c, d). In contrast, in the AC and hippocampus (Fig. 1c, d), TrkC-Cre-ROSA26R but not Pax2-CreROSA26R mice exhibited $\beta$-gal staining (Fig. 1c, d). A similar deletion pattern of BDNF in both $\mathrm{BDNF}^{\text {Pax2 }}-\mathrm{KO}$ and $\mathrm{BDNF}^{T r k C}-\mathrm{KO}$ mice was confirmed by the almost complete loss of the 4-kB and 1.8-kB BDNF transcripts and the absence of the 14-kDa BDNF polypeptide using Northern and Western blots, respectively (Fig. 1e, f, IC) [25]. In contrast, only in $\mathrm{BDNF}^{\text {TrkC }}-\mathrm{KO}$ but not $\mathrm{BDNF}^{\text {Pax } 2}-\mathrm{KO}$ mice, BDNF mRNA and protein were absent at the level of the AC (Fig. 1e, f) [25]. The overall deletion pattern is summarized in Fig. $1 \mathrm{~g}$, f. In the IC, $\beta$-gal (Fig. 2a, d, green) and BDNF immunoreactivity (Fig. 2c, f, red) were found in PV-immunopositive and PVimmunonegative neurons in both $\mathrm{BDNF}^{\text {Pax2 }}$-WT and $\mathrm{BDNF}^{T r k C}$-WT mice. The specificity of BDNF staining in these neurons was confirmed using $\mathrm{BDNF}^{\text {Pax } 2}-\mathrm{KO}$ and $\mathrm{BDNF}^{T r k C}-\mathrm{KO}$ animals (Fig. 2c, f). Colabeling with the neuronal microtubule-associated protein MAP2 and the glutamatergic marker protein VGLUT2 indicated that PVimmunoreactive neurons in the IC may correspond to projection neurons (not shown). On the other hand, colabeling of $\beta$ - gal with either the oligodendrocyte marker GFAP or the microglia marker Iba1 [48] in Pax2-Cre-ROSA26R and TrkCCre-ROSA26R mice (Fig. 2b, e) confirmed that $\beta$-gal was preferentially localized in the neurons of the IC.

Therefore, $\mathrm{BDNF}^{P a x 2}-\mathrm{KO}$ and $\mathrm{BDNF}^{T r k C}-\mathrm{KO}$ mice exhibit comparable BDNF deletion profiles in the IC, DCN, and SGNs (Fig. 1g, h, green dots) and were expected to develop similar hearing defects.

\section{Deletion of BDNF in BDNF ${ }^{\text {Pax2 }}$-KO but not BDNF $^{\text {TrkC }}$-KO Mice Constricts Sound-Induced ABR Waves}

We thus measured hearing function in both BDNF mutant strains as described previously [25] and were surprised to observe significant differences. As shown in Fig. 3a (upper panel), $\mathrm{BDNF}^{\text {Pax } 2}-\mathrm{KO}$ mice exhibited slightly increased hearing thresholds (WTc, $n=6 / 12$ ears/mice, $18.6 \pm 3.92 ; \mathrm{KOc}, n=6 / 12$ ears/mice, $30.3 \pm 5.3$; one-way ANOVA $p<0.001$; n.s. not significant; ${ }^{* *} p<0.001$ Bonferroni's multiple comparison test), which have been linked with reduced exocytosis and ribbon numbers in otherwise mature IHC synapses in high-frequency cochlear turns [25]. After noise exposure, the loss of hearing thresholds in $\mathrm{BDNF}^{\text {Pax2 }}$-KO animals is, however, significantly less pronounced than in $\mathrm{BDNF}^{\text {Pax2 }}$-WT mice (Fig. 3a, upper panel, WTat, $n=8 / 16$ ears/mice, $64.5 \pm 16.64$; KOat, $n=8 / 16$ ears/mice, $41.9 \pm 16.71$; one-way ANOVA $p<0.001$; n.s. not significant; ${ }^{* *} p<0.001$ Bonferroni's multiple comparison test) [25]. In contrast, $\mathrm{BDNF}^{T{ }^{T K C}}$-KO mice did not exhibit any differences in hearing thresholds compared to age-matched BDNF $^{\text {TrkC }}$-WT mice, as assessed by click-evoked (Fig. 3a, lower panel, WTc, $n=22 / 11$ ears/mice, $19.6 \pm 6.38$; KOc, $n=20 / 10$ ears/mice, 20.7 $\pm 7.52 ; p=0.999)$ and frequency-dependent (Fig. 3b, WTc, $n=22 / 11$ ears/mice; KOc, $n=10 / 10$ ears/mice; $p=0.684$ ) hearing measurements before and after AT (Fig. 3a, WTat, $n=8 / 8$ ears $/$ mice, $40.7 \pm 19.54$; KOat, $n=7 / 7$ ears $/$ mice, $48.0 \pm 18.03 ; p=0.543$ for click-evoked ABR, $p=0.419$ for frequency-dependent ABR). Also, mean numbers of IHC ribbons in $\mathrm{BDNF}^{T r k C}-\mathrm{KO}$ mice before and after AT were similar to that in $\mathrm{BDNF}^{T r k C}$-WT mice (Fig. 3d). This indicates that the BDNF deletion under the Pax 2 but not the TrkC promoter slightly reduced sound sensitivity.

Despite the differences in hearing thresholds, $\mathrm{BDNF}^{T r k C}-\mathrm{KO}$ and $\mathrm{BDNF}^{\mathrm{Pax} 2}-\mathrm{KO}$ mice did not differ in $\mathrm{OHC}$ function, based on DPOAEs (Fig. 3c, $n=20 / 10$ ears/mice) [25]. Consistent with BDNF acting at the level of the IHC-afferent nerve fiber, suprathreshold amplitudes of spreading auditory nerve activity (wave I) and midbrain activity (lateral lemniscus and IC, wave IV) were significantly reduced before AT but less affected after $\mathrm{AT}$ in $\mathrm{BDNF}^{\text {Pax2 }}$-KO compared to $\mathrm{BDNF}^{\text {Pax }}$-WT mice (Fig. 3e, WTat, $n=8$; KOat, $n=8$ ). This effect was not observed in $\mathrm{BDNF}^{T r k C}-\mathrm{KO}$ animals (Fig. 3f, wave I: $p=0.885$, wave IV: $p=0.814 ; \mathrm{WTc}, n=17 / 9$ ears/mice; KOc, $n=15 / 8$ ears/mice; 

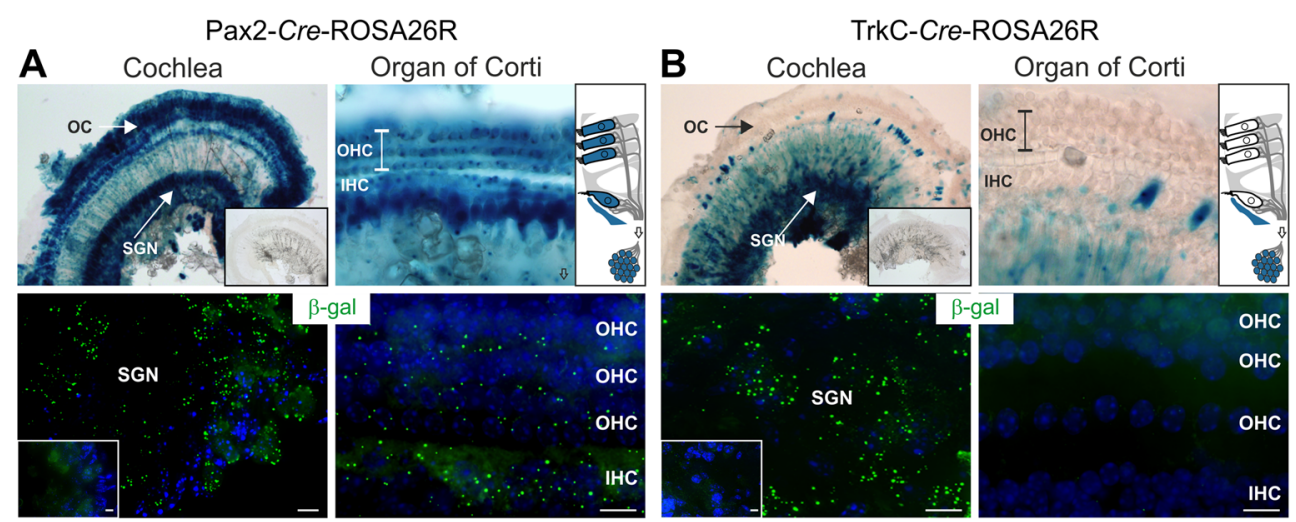
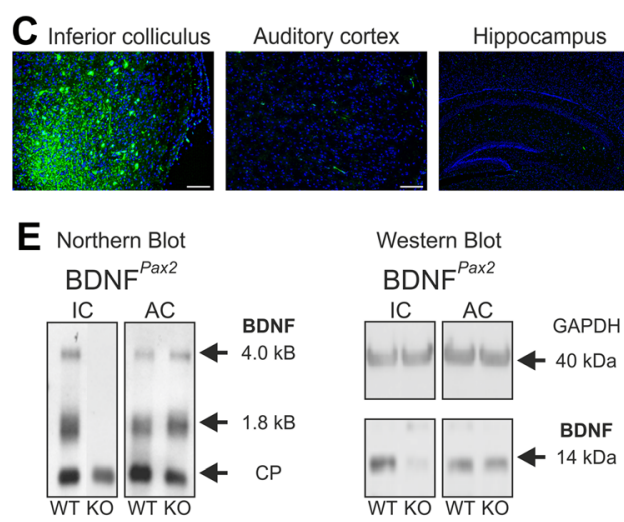

G

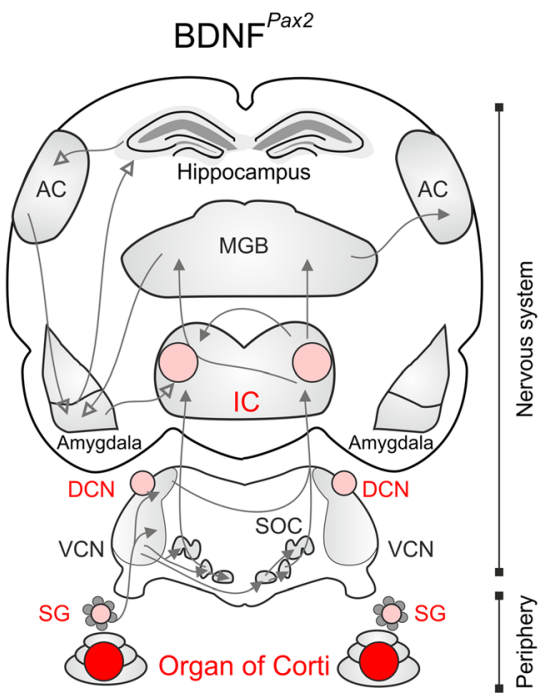

Fig. 1 Differential BDNF deletion patterns under the Pax2 or the TrkC promoter. a, $\mathbf{b} \mathrm{X}$-gal staining and $\beta$-gal immunolabeling of mice carrying the Pax2-Cre (a) or the TrkC-Cre transgene (b) on a ROSA26R background. a In the mature cochlea, $\beta$-galactosidase activity in Pax2Cre-ROSA26R mice was detected in inner $(I H C)$ and outer hair cells $(O H C)$ of the organ of Corti $(O C)$ and in spiral ganglion neurons $(S G N)$. b $\beta$-Galactosidase activity in TrkC-Cre-ROSA26R mice was detected mainly in SGNs, but not in hair cells, as demonstrated by immunohistochemistry. c Immunohistochemistry for $\beta$-gal in the inferior colliculus $(I C)$, auditory cortex $(A C)$, and hippocampus of Pax2-Cre-ROSA26R mice. In the IC, $\beta$-gal staining can be detected, whereas no expression is observed in the $\mathrm{AC}$ and hippocampus. d Immunohistochemistry for $\beta$-gal in the IC, AC, and hippocampus of TrkC-Cre-ROSA26R mice. Clear $\beta$-gal staining is observed in the IC, $\mathrm{AC}$, and hippocampus. In Cre-negative mice, no $\beta$-gal staining is seen

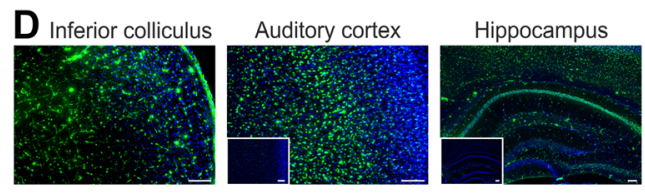

\section{F Northern Blot} BDNF $^{\text {TrkC }}$

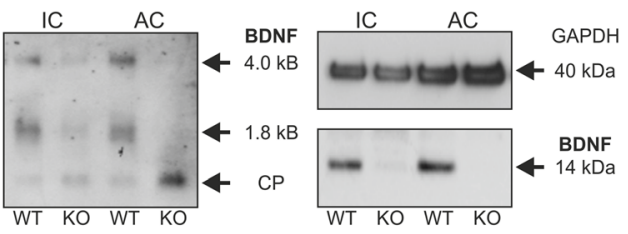

H

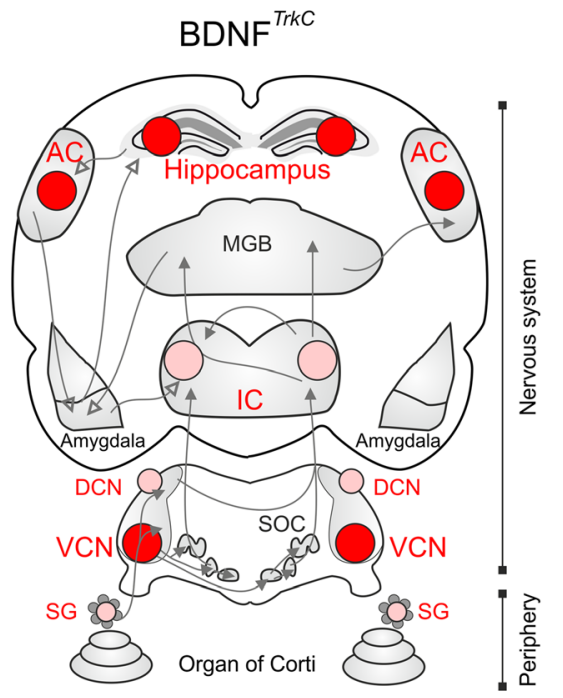

(insets). Scale bars $=\mathbf{a}, \mathbf{b} 10 \mu \mathrm{m} ; \mathbf{c}, \mathbf{d} 100 \mu \mathrm{m}$. e Northern and Western blots from IC and AC tissues of wild-type (WT) and BDNF ${ }^{\text {Pax } 2}$ knockout $(K O)$ mice demonstrating a deletion of BDNF mRNA isoforms (1.8 and $4 \mathrm{~kb})$ and BDNF protein $(14 \mathrm{kDa})$ in the IC but not in the AC of $\mathrm{BDNF}^{\text {Pax } 2}$-KO mice. f Northern and Western blots from IC and AC tissues of WT and $\mathrm{BDNF}^{T r k C}-\mathrm{KO}$ mice demonstrating a deletion of BDNF mRNA isoforms $(1.8$ and $4 \mathrm{~kb})$ and protein $(14 \mathrm{kDa})$ in the IC and $\mathrm{AC}$ of BDNF ${ }^{T r k C}-\mathrm{KO}$ mice. For Northern blots, cyclophilin $(C P)$ was used as a reference $(0.8 \mathrm{~kb})$; for Western blots, GAPDH $(40 \mathrm{kDa})$ was used as a loading control. $\mathbf{g}, \mathbf{h}$ Diagrams of the auditory pathway: the area of BDNF deletion exclusively in either the BDNF ${ }^{\operatorname{Pax}^{2}}-\mathrm{KO}$ or the $\mathrm{BDNF}^{\text {TrkC }}-\mathrm{KO}$ is marked in dark red; the area of BDNF deletion in both BDNF-KO mouse lines is marked in bright red. $\mathbf{g}$ BDNF deletion in $\mathrm{BDNF}^{\text {Pax2 }}-\mathrm{KO}$ mice, $\mathbf{h} \mathrm{BDNF}$ deletion in $\mathrm{BDNF}^{\text {TrkC }}-\mathrm{KO}$ mice 
Inferior colliculus

Pax2-Cre-ROSA26R
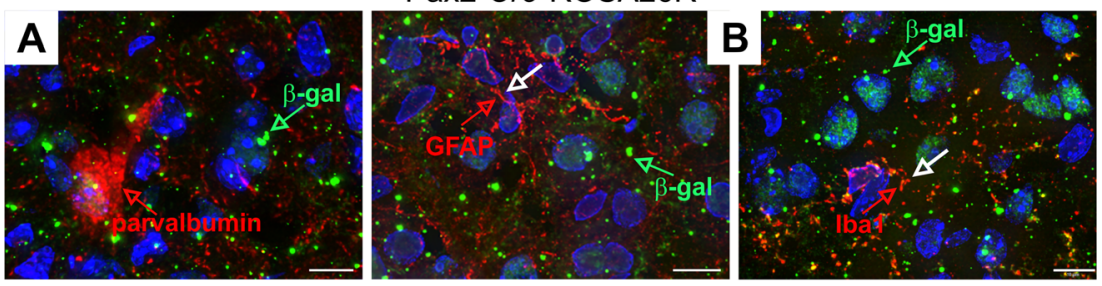

C

BDNF $^{\text {Pax2 }}-\mathrm{WT}$
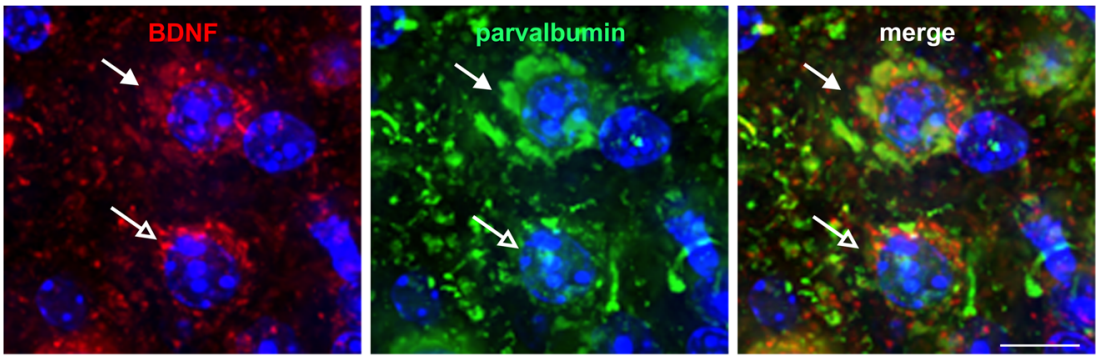

$\mathrm{BDNF}^{\text {Pax2}}-\mathrm{KO}$
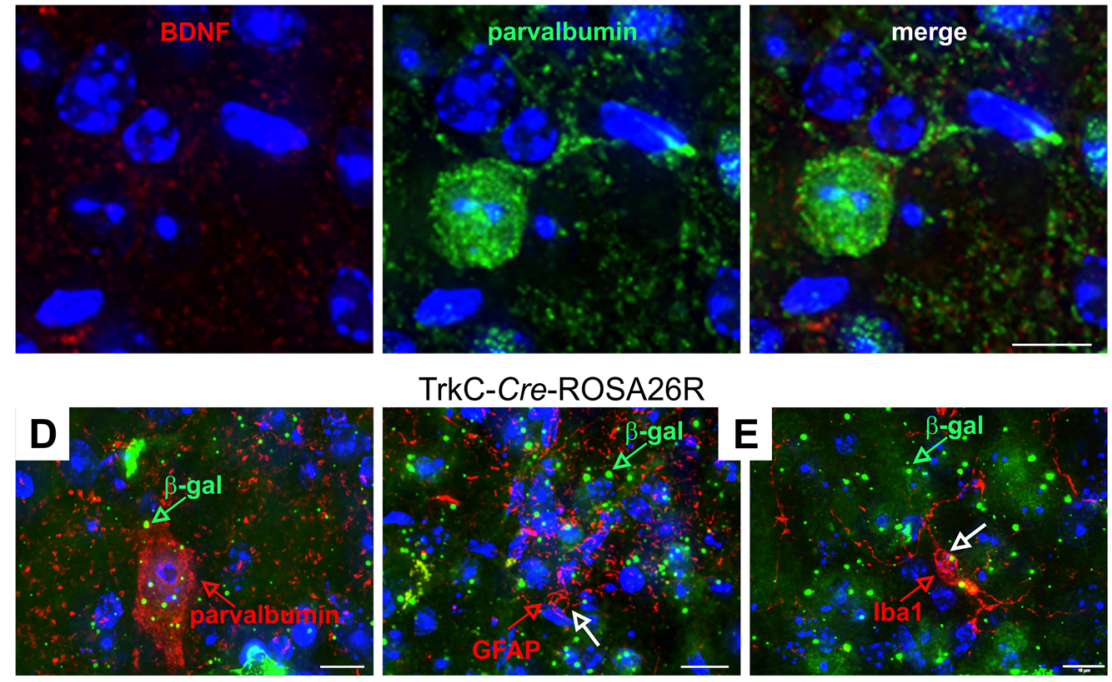

TrkC-Cre-ROSA26R
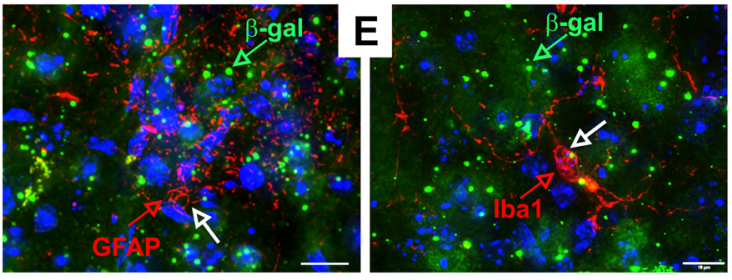

F

BDNF $^{T r k C}-W T$
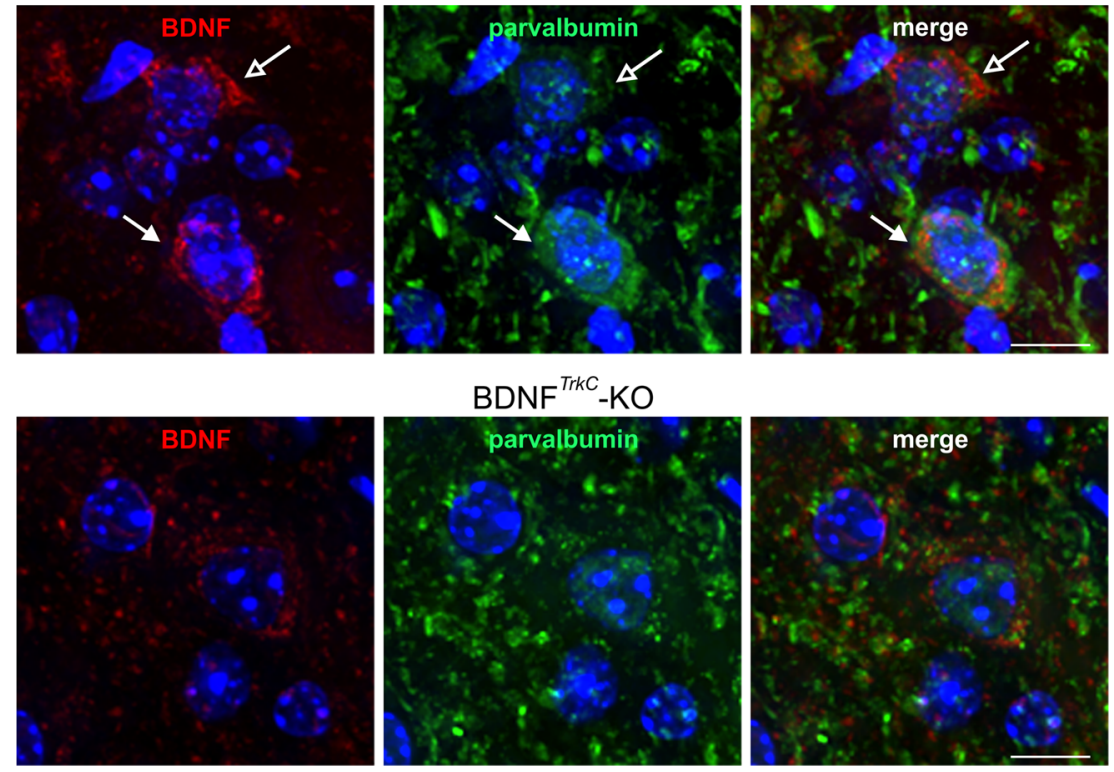
4 Fig. 2 Immunohistochemistry of the IC of Pax2-Cre-ROSA26R and TrkC-Cre-ROSA26R mice and $\mathrm{BDNF}^{\text {Pax2 }}$ and $\mathrm{BDNF}^{\text {TrkC }} \mathrm{WT}$ and $\mathrm{KO}$ mice. a, d Immunostaining with anti- $\beta$-galactosidase ( $\beta$-gal, green) and anti-parvalbumin (red) showing coexpression of $\beta$-galactosidase and parvalbumin in IC sections from both Pax2- and TrkC-Cre-ROSA26R mice. $\mathbf{b}$, e Co-immunostaining with anti- $\beta$-galactosidase ( $\beta$-gal, green) and either the oligodendrocyte marker anti-GFAP (red, open arrow) or the microglia marker anti-Ibal (red, open arrow) in IC sections from both Pax2- and TrkC-Cre-ROSA26R mice shows no coexpression of $\beta$ galactosidase and GFAP or Iba1. Therefore, $\beta$-galactosidase is detected in neuronal cells. c, f Immunohistochemistry of IC sections stained with anti-BDNF (red) and anti-parvalbumin (green) antibodies, showing BDNF immunoreactivity in PV-positive and PV-negative neurons in $\mathrm{BDNF}^{\text {Pax2 }}$-WT (c, upper row) and $\mathrm{BDNF}^{\text {TrkC }}$-WT (f, upper row) mice. Closed arrows indicate cells positive for BDNF (red) and parvalbumin (green). Open arrows indicate cells expressing only BDNF (red). The specificity of the BDNF antibody is shown by the lack of BDNF immunostaining in $\mathrm{BDNF}^{\text {Pax }^{2}}-\mathrm{KO}$ and $\mathrm{BDNF}^{\text {TrkC }}-\mathrm{KO}$ mice $(\mathbf{c}, \mathbf{f}$, lower rows). Scale bars $=10 \mu \mathrm{m}$

control "c" vs. acoustic trauma "at": WTc, $n=8 / 4$ ears/mice; KOc, $n=8 / 4$ ears/mice; WTat, $n=8 / 4$ ears/mice; KOat, $n=7 / 4$ ears/mice). Likewise, the growth of suprathreshold ABR amplitudes to increasing sound intensities was affected in $\mathrm{BDNF}^{\text {Pax } 2}-\mathrm{KO}$ but not in $\mathrm{BDNF}^{\text {TrkC }}-\mathrm{KO}$ mice (compare Fig. $3 g$, h with i, j). Whereas ABR waves I and IV of traumatized $\mathrm{BDNF}^{\text {Pax2 }}-\mathrm{KO}$ mice were significantly less elevated in comparison to those of $\mathrm{BDNF}^{\text {Pax } 2}$-WT mice, no significant variations in DPOAEs ( $p=0.056, n=8 / 4$ ears/mice) were observed after AT. Also the SPLs that generated significant differences in ABR wave I and IV $20 \mathrm{~dB}$ above thresholds in $\mathrm{BDNF}^{\text {Pax } 2}-\mathrm{WT}$ and $\mathrm{BDNF}^{\text {Pax2 }}-\mathrm{KO}$ (Fig. 3g, h) were far beyond the stimulus levels (15-30 dB SPL) where variations in the DPOAE response between $\mathrm{BDNF}^{\text {Pax2 }}-\mathrm{WT}$ and $\mathrm{BDNF}^{\text {Pax2 }}$ $\mathrm{KO}$ mice were apparent [25]. Therefore, in the range of the stimulus levels in which the ABR functions were quantified, no difference in DPOAE responses can be found between $\mathrm{BDNF}^{\text {Pax } 2}-\mathrm{WT}$ and $\mathrm{BDNF}^{\text {Pax } 2}-\mathrm{KO}$ animals. This indicates that the BDNF deletion under the Pax 2 promoter may reduce sound sensitivity independently of $\mathrm{OHC}$ functions.

To further strengthen the point that the threshold differences between $\mathrm{BDNF}^{\text {Pax } 2}-\mathrm{WT}$ and $\mathrm{BDNF}^{\text {Pax } 2}-\mathrm{KO}$ are not caused by defects in $\mathrm{OHC}$ function, the phenotype of OHCs and their efferent and afferent synapses were studied in more detail. As exemplarily shown for midbasal turns, no obvious differences of the morphology of pre- and postsynapses of OHCs were observed between $\mathrm{BDNF}^{\text {Pax } 2}-\mathrm{WT}$ and $\mathrm{BDNF}^{\text {Pax2 }}$-KO mice. This was judged on the basis of expression of $\mathrm{OHC}$ marker proteins such as the outward-rectifying potassium channel KCNQ4 (Fig. 4a) or the $\mathrm{Ca}^{2+}$-binding protein parvalbumin (Fig. 4b). Also markers for pre- and postsynaptic efferent contacts such as SK2 and BK (Fig. 4c, d) $[49,50]$ and the numbers of CtBP2-stained OHC ribbons were similar between $\mathrm{BDNF}^{\text {Pax } 2}-\mathrm{WT}$ and $\mathrm{BDNF}^{\text {Pax } 2}-\mathrm{KO}$ mice (Fig. 4e, g), whereas IHC ribbons in the latter animals were reduced (Fig. 4f, g).
These findings suggest that BDNF deletion under the Pax2 but not the TrkC promoter reduced evoked sound amplitudes independently of $\mathrm{OHC}$ function. After AT, the weaker reduction of amplitudes in $\mathrm{BDNF}^{\text {Pax2 }}-\mathrm{KO}$ pointed to a sound sensitivity that cannot be lost after AT, because it has never been enhanced via a sensory experience by BDNF.

The similar deletion profiles of BDNF in $\mathrm{BDNF}^{\text {Pax } 2}-\mathrm{KO}$ and $\mathrm{BDNF}^{\text {TrkC }}-\mathrm{KO}$ mice shown by immunohistochemistry and Western and Northern blot analyses in the IC suggest that the $\mathrm{IC}$ is unlikely to be the BDNF source responsible for the altered sound sensitivity observed in $\mathrm{BDNF}^{\operatorname{Pax}^{2}}-\mathrm{KO}$ mice. As BDNF in the VCN or olivary complex is not deleted using the Pax2 promoter [25], the effects of BDNF acting from the superior olivary complex are also unlikely to play a role. Finally, since $\mathrm{BDNF}$ released from projection neurons is assumed to drive interneuron stability and not vice versa [51], loss of BDNF in PV-expressing inhibitory interneurons that are suggested to derive from Pax2 precursors [52] is probably not involved in the auditory phenotype of BDNF ${ }^{\text {Pax } 2}-\mathrm{KO}$ mice. Therefore, influences from intracortically expressed BDNF acting through descending pathways are very unlikely to be the underlying cause for the auditory phenotype in the $\mathrm{BDNF}^{\operatorname{Pax}^{2}}-\mathrm{KO}$ animals, as in these mice BDNF is not deleted in the AC (Fig. 1c). Thus, BDNF in the lower parts of the auditory CNS or within the cochlea has to be considered as the most likely source responsible for altered sound sensitivity before and after AT in $\mathrm{BDNF}^{\text {Pax2 }}-\mathrm{KO}$ mice.

\section{Deletion of BDNF in BDNF ${ }^{\text {Pax2 }}$-KO Constricts CF Thresholds and Dynamic Range in IC Neurons}

To understand the physiology behind the reduced range of suprathreshold ABR responses generated at the level of the IC in $\mathrm{BDNF}^{\text {Pax2 }^{2}}$-KO mice (Fig. 3e, h), we analyzed the electrophysiological response behavior of single IC neurons in 3-4month-old BDNF ${ }^{\text {Pax } 2}$-WT and BDNF ${ }^{\text {Pax } 2}$-KO mice, 3-4 weeks after sham or traumatizing acoustic exposure. The responses to $\mathrm{BBN}$ and pure tones of a total of $1069 \mathrm{IC}$ units were recorded, comprising 264 units from WTc $(n=4), 232$ from KOc $(n=4)$, 254 from WTat $(n=5)$, and 404 from KOat $(n=5)$.

Since AT was produced by exposure to a $10-\mathrm{kHz}$ pure tone, the whole sample of units was divided into three main nonoverlapping frequency bands according to their CF: 4-9 kHz (low), 10-15 kHz (middle), and 16-30 kHz (high). The thresholds of IC neurons to BBN stimulation were significant-

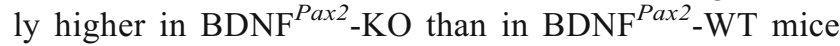
(Fig. 5a, BDNF ${ }^{\text {Pax } 2}-\mathrm{KOc}, 38.62 \pm 9.6 \mathrm{~dB}$ SPL; BDNF ${ }^{\text {Pax } 2}$ WTc, $24.78 \pm 10.76 \mathrm{~dB} \mathrm{SPL} ; * * * * p<0.0001)$. After AT, in KO animals ( $\sim 20 \mathrm{~dB})$, these thresholds were significantly less pronounced than in WT mice ( $40 \mathrm{~dB}$; Fig. 5a, b). Also, response thresholds to tone stimulation at neuronal $\mathrm{CF} 10$ $15 \mathrm{kHz}$ and $16-30 \mathrm{kHz}$ were significantly higher in

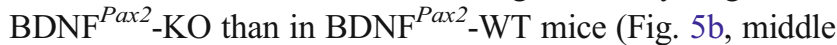


A

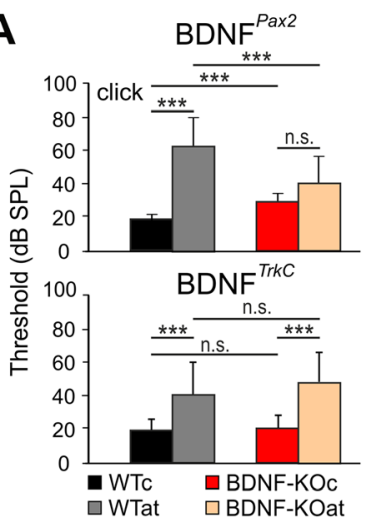

D

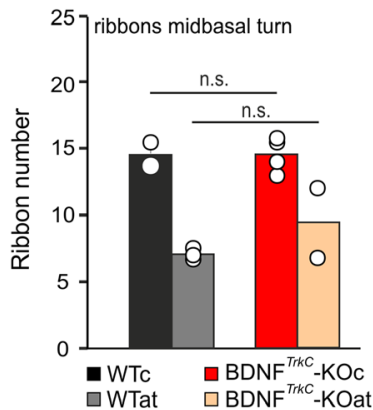

$\mathbf{B}$

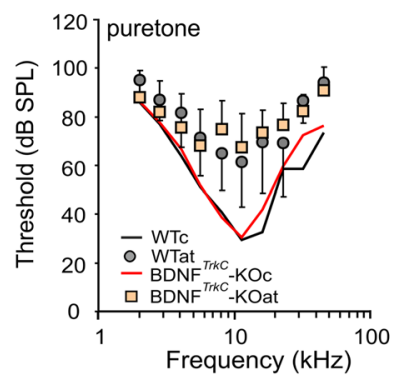

E
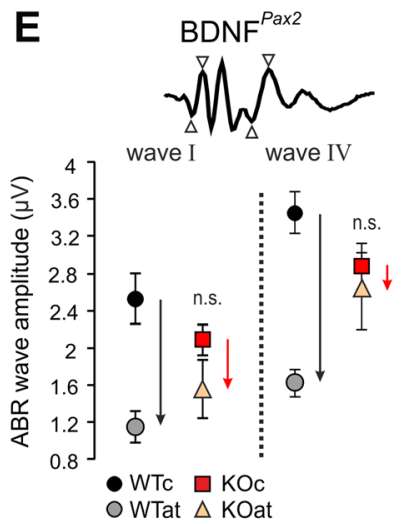

C $\quad \mathrm{BDNF}^{\mathrm{T} K \mathrm{C}}$
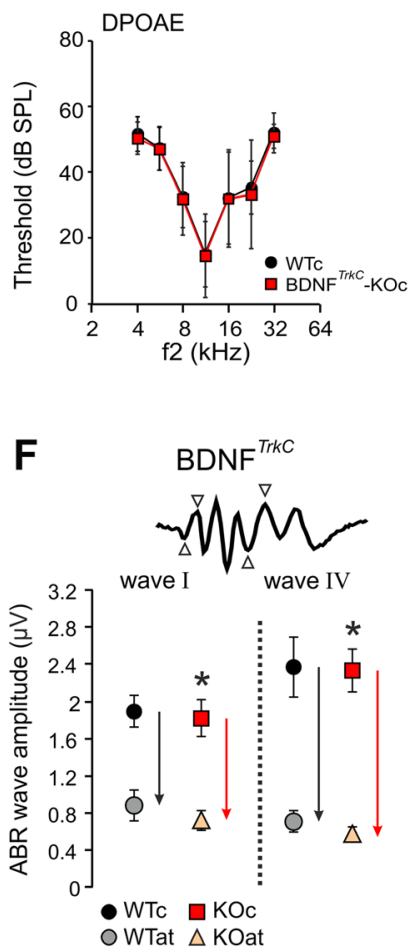
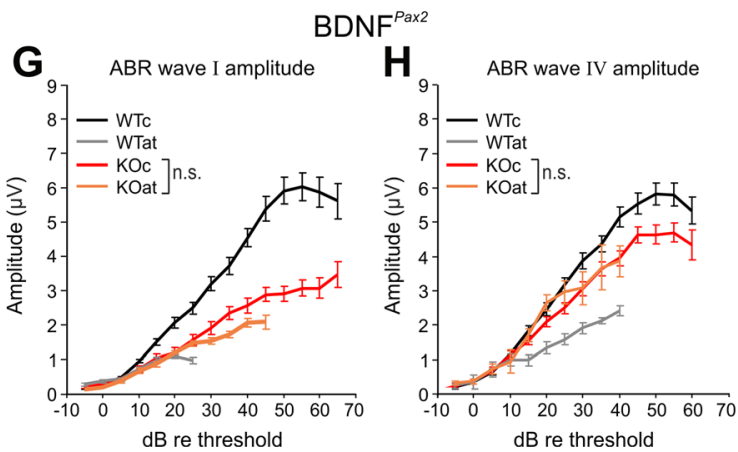

Fig. 3 Hearing function of $\mathrm{BDNF}^{\text {Pax } 2}-\mathrm{KO}$ and $\mathrm{BDNF}^{\text {TrkC }}-\mathrm{KO}$ mice before and after acoustic trauma. Auditory thresholds of $\mathrm{BDNF}^{\text {Pax2 }}-\mathrm{KO}$ (a, upper panel) and $\mathrm{BDNF}^{\text {TrkC }}$-KO (a, lower panel) mice analyzed by click (a) and tone-burst-evoked ABR (b) before (KOc) and after acoustic trauma (KOat). Compared to WT mice (WTc, WTat), $\mathrm{BDNF}^{\text {Pax }}$-KO are less vulnerable [25]. $\mathrm{BDNF}^{T r k C}-\mathrm{KO}$ mice exhibited normal hearing thresholds (a, lower panel, WTc, ears/mice: $n=22 / 11$; KOc, $n=20 / 10$; $p>0.999$, two-way ANOVA) and show no significant difference to WT mice after acoustic trauma (WTat, ears/mice: $n=8 / 8$; KOat, $n=7 / 7$; $p=$ 0.543, two-way ANOVA). Error bars, SD. c DPOAE thresholds in $\mathrm{BDNF}^{T r k C}$-WT and BDNF ${ }^{\text {TrkC }}$-KO mice were similar (WT, ears/mice: $n=19 / 10 ; \mathrm{KOn}=20 / 10 ; p=0.482$, two-way ANOVA). Error bars, SD. d $\mathrm{IHC}$ ribbon counts of midbasal cochlear turns in $\mathrm{BDNF}^{\text {TrkC }}-\mathrm{WT}$ and $\mathrm{BDNF}^{T r k C}-\mathrm{KO}$ mice before (WTc, KOc) and after noise exposure (WTat, KOat). The ribbon number of $\mathrm{BDNF}^{T r k C}-\mathrm{KO}$ mice was not significantly different from that of $\mathrm{BDNF}^{\text {TrkC }}$-WT animals. Error bars, SEM, n.s. $p>0.05$; WTc, sections/mice: $n=5 / 2$; WTat, $n=6 / 3$; KOc, $n=$ 11/4; KOat, $n=7 / 2$. e, f Comparison of click-evoked ABR wave amplitudes in $\mathrm{BDNF}^{\text {Pax } 2}-\mathrm{WT}$ and $\mathrm{BDNF}^{\text {Pax } 2}-\mathrm{KO}$ mice (e) and $\mathrm{BDNF}^{T r k C}$-WT (WTc, WTat) and $\mathrm{BDNF}^{T r k C}-\mathrm{KO}$ (KOc, KOat) mice (f) before (WTc, KOc) and after noise exposure (WTat, KOat). In

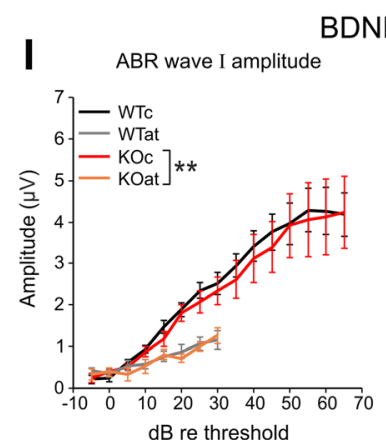

BDNF

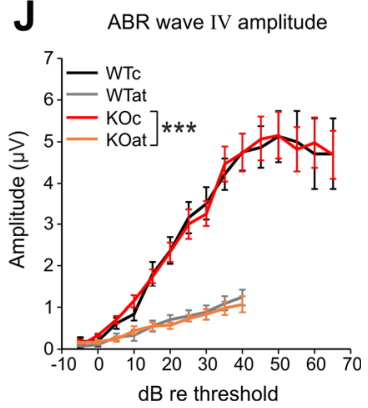

$\mathrm{BDNF}^{\operatorname{Pax} 2}-\mathrm{KO}$, suprathreshold amplitudes of wave I (auditory nerve) and wave IV (IC) are less reduced after noise exposure than in $\mathrm{BDNF}^{\text {Pax2 }}$-WT mice (compare black and red arrows in e for different

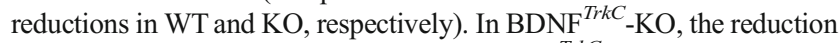
was not different from the reduction in $\mathrm{BDNF}^{T r k C}$-WT mice (compare black and red arrows in $\mathbf{f}$ for similar reduction in WT and $\mathrm{KO}$, respectively). Two-way ANOVA with Bonferroni's post hoc test (e) wave I, n.s. $p=0.254$; wave IV, n.s. $p=0.893$; WTat, ears/mice: $n=8 / 4$; KOat, $n=7 / 4$; f wave I, ${ }^{*} p=0.04$; wave IV, ${ }^{*} p=0.02$; WTat, mice/ears: $n=$ 8/16; KOat, $n=8 / 16$; error bars, SEM. g-j Suprathreshold ABR amplitude at the level of the auditory nerve (wave I) and IC (wave IV). Analysis was performed before and after acoustic trauma in $\mathrm{BDNF}^{\text {Pax } 2}$. WT (WTc, $n=16 / 8$ ears/mice; WTat, $n=16 / 8$ ears/mice) and $\mathrm{BDNF}^{\text {Pax } 2}$. KO mice (KOc, $n=16 / 8$ ears/mice; KOat, $n=16 / 8$ ears $/$ mice) $(\mathbf{g}, \mathbf{h})$ compared to $\mathrm{BDNF}^{\text {TrkC }}$-WT (WTc, $n=17 / 8$ ears/mice; WTat, $n=8$ / 4 ears/mice) and $\mathrm{BDNF}^{\text {TrkC }}$-KO mice (KOc, $n=15 / 8$ ears/mice; KOat, $n=7 / 4$ ears/mice) (i, j). Note the near-complete convergence of growth functions of ABR wave I (g, n.s. $p=0.275 ; \mathbf{i}, * * p=0.008)$ and IV (h, n.s. $p=0.420 ; \mathbf{j},{ }^{* *} p<0.001$ ) before and after AT in $\mathrm{BDNF}^{\text {Pax2 }}-\mathrm{KO}$ but not in $\mathrm{BDNF}^{\text {TrkC }}$-KO mice. Two-way ANOVA with Bonferroni's post hoc test, error bars, SEM 

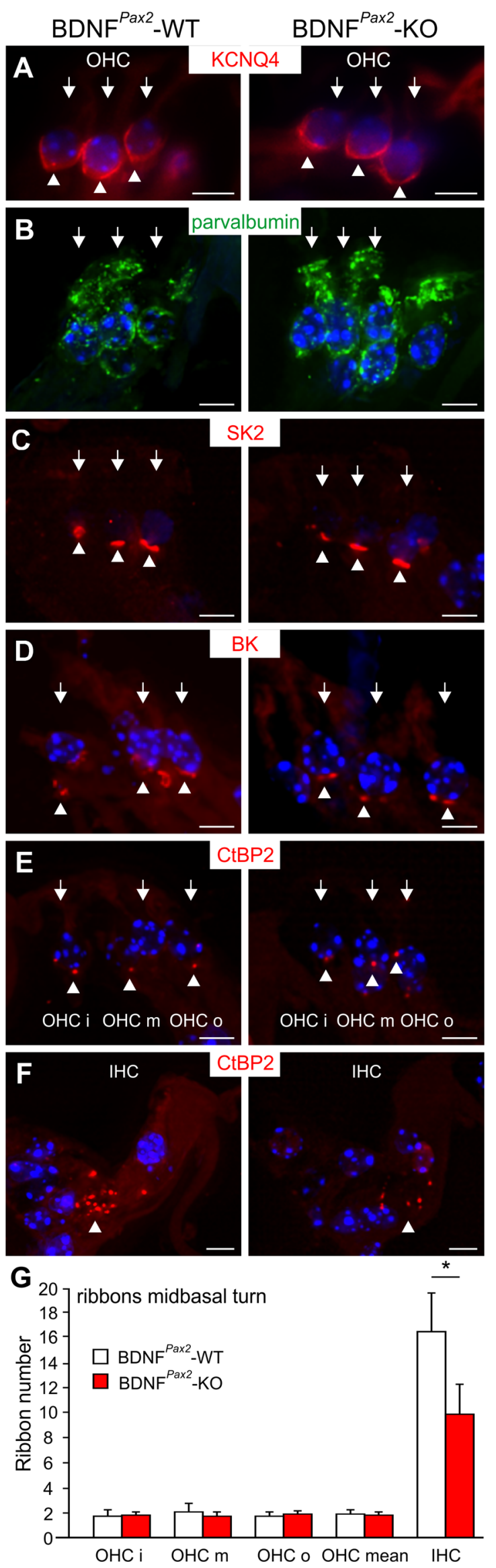

Fig. 4 Immunohistochemistry of outer hairs cells $(O H C$, arrows $)$ in $\mathrm{BDNF}^{\text {Pax } 2}$-WT $(n=4$, left panels $)$ and $\mathrm{BDNF}^{\text {Pax } 2}-\mathrm{KO}(n=4$, right panels) mice. OHCs are stained for the voltage-gated potassium channel KCNQ4 (a), parvalbumin (b), the small conductance calciumactivated potassium channel SK2 (c), the large-conductance calciumactivated potassium channel BK (d), and CtBP2, a marker of ribbon synapses (e). f In contrast to OHCs, IHCs show reduced number of CtBP2-stained ribbons in $\mathrm{BDNF}^{\text {Pax }}$-KO mice. Arrowheads indicate antibody staining. g Quantification of ribbons stained with anti-CtBP2. No differences are observed in any row of the OHCs or in the mean ribbon number of OHCs, although a significantly reduced ribbon number can be seen in IHCs. Two-tailed unpaired Student's $t$ test with $\alpha=5\left({ }^{*} p<0.05\right)$. Scale bars $=5 \mu \mathrm{m}$

CF, WTc: $M d n=19.18$; KOc: $\operatorname{Mdn}=35.14,{ }^{* *} p<0.01$; high CF, WTc: $\operatorname{Mdn}=30.28$; KOc: $\operatorname{Mdn}=39.38, * * * p<0.001$ ) and tended to be smaller after $\mathrm{AT}$ in $\mathrm{BDNF}^{\text {Pax2 }}-\mathrm{KO}$ mice in these $\mathrm{CF}$ ranges (Fig. 5b). Low $\mathrm{CF}$ thresholds in $\mathrm{BDNF}^{\text {Pax2 }}$ KO mice were not significantly different from WT, even though no units with thresholds below $\sim 30 \mathrm{~dB}$ SPL could be found (Fig. 5b, WTc: $\mathrm{Mdn}=24.34$; KOc: $\mathrm{Mdn}=40.39$, n.s. $p>0.05$ ). Thresholds of individual IC neurons as a function of $\mathrm{CF}$ are presented in scatter plots for $\mathrm{BDNF}^{\text {Pax } 2}-\mathrm{WT}$ and $\mathrm{BDNF}^{\text {Pax2 }}$-KO animals (Fig. 5c). Finally, the parameters of the RIFs such as dynamic range (WTc $52.37 \pm 11$; KOc 43.23 $\pm 11, * * * * p<0.0001$ ) and slope (WTc $0.01424 \pm 0.006$; KOc $0.01919 \pm 0.007, * * * *<0.0001)$, but not maximum response magnitude (WTc 20.52 \pm 12.48 ; KOc $21.83 \pm 15.56$, n.s. $p>0.05$ ) of IC neurons, were significantly reduced in $\mathrm{BDNF}^{P a x 2}-\mathrm{KO}$ mice and significantly less pronounced after $\mathrm{AT}$ in $\mathrm{BDNF}^{\text {Pax } 2}$-KO than in $\mathrm{BDNF}^{\text {Pax }}$-WT mice (Fig. 5d, e).

These findings reveal that after the onset of hearing, BDNF in lower brain parts improves sound-evoked ABR amplitudes generated at the level of the IC (ABR wave IV amplitudes) as well as the threshold to which IC neurons can respond to sound intensities above $10 \mathrm{kHz}$. This sensitivity to sound can be lost after auditory nerve injury in the mature system only when it has been established before with the onset of hearing.

\section{Deletion of BDNF in BDNF ${ }^{P a x}$-KO Mice Alters Latency and Tuning Characteristic of IC Neurons}

CF detection thresholds have been hypothesized to be influenced by onset stimuli [53]. Differences in onset stimuli should be reflected by differences in $\mathrm{mFSL}$, which can be evaluated from poststimulus time histograms. mFSLs for $80 \mathrm{~dB}$ SPL stimuli were similar in $\mathrm{BDNF}^{\text {Pax2 }}$-WT and $\mathrm{BDNF}^{\text {Pax2 }}-\mathrm{KO}$ animals for the low- and middle-frequency bands (Fig. 6a; low CF, 4-9 kHz, WTc: $M d n=7.28$; KOc: $M d n=7.4$, n.s. $p>0.05$; middle CF, 10-15 kHz, WTc: $M d n=6.8$; KOc: $M d n=6.9$, n.s. $p>0.05$ ), but were significantly longer for neurons with high

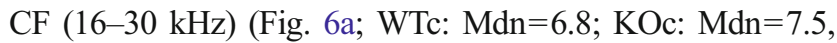
$* * * * p<0.0001)$. After AT, mFSLs were less enlarged in $\mathrm{BDNF}^{\operatorname{Pax} 2}-\mathrm{KO}$ mice for neurons with both middle and high 
A
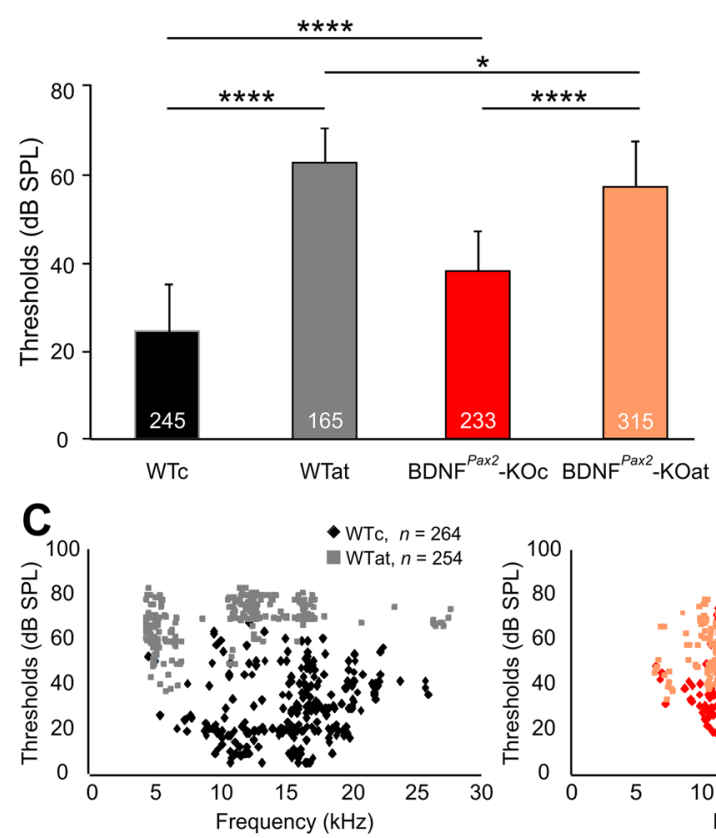

E

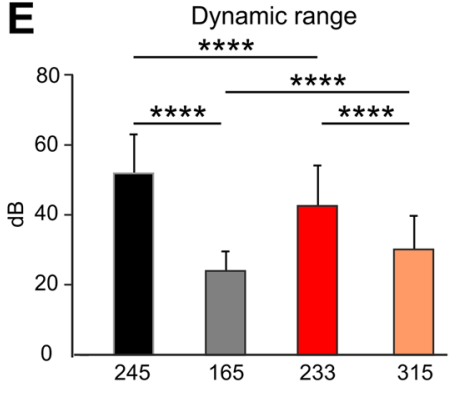

B

Thresholds (tone-evoked responses)
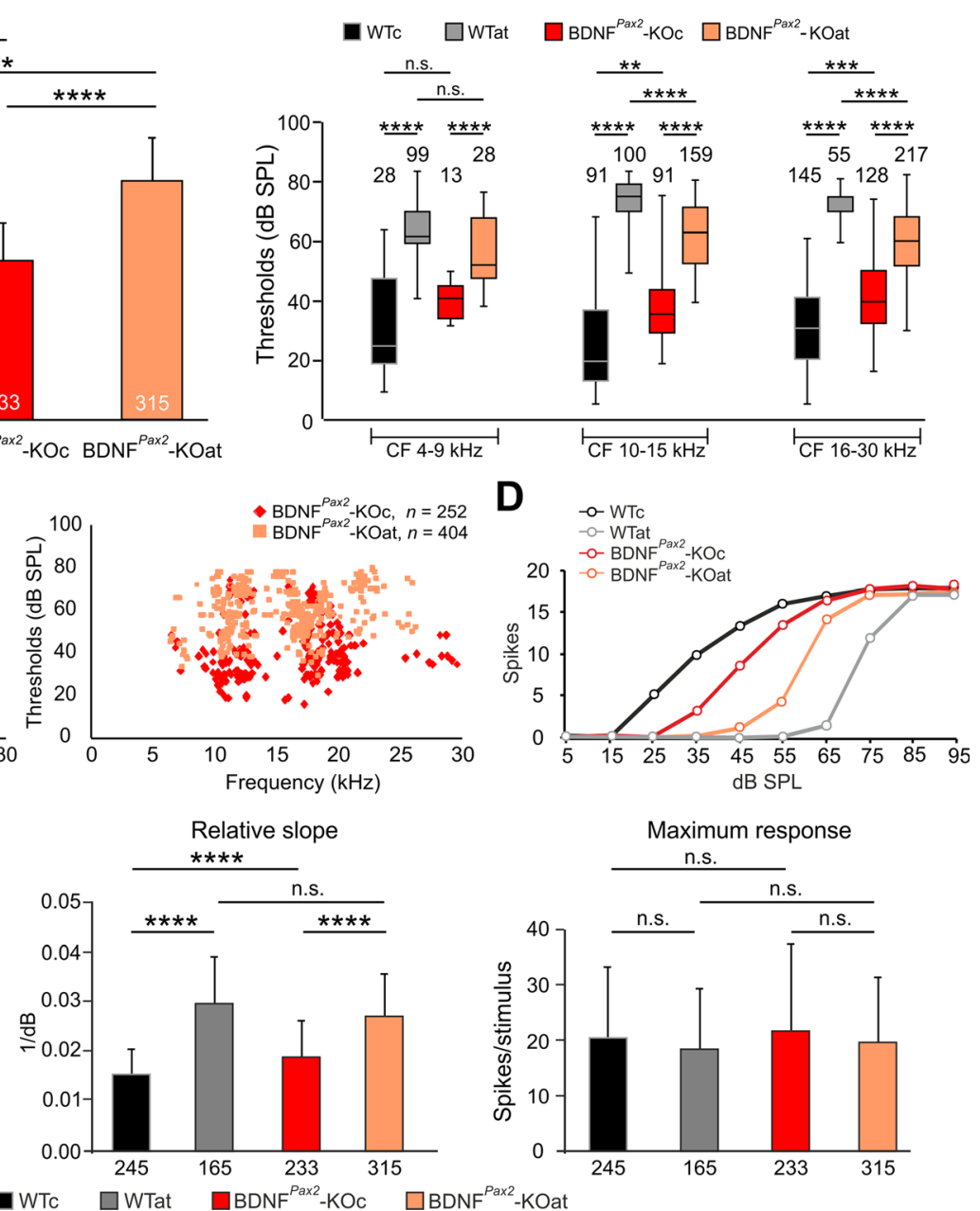

Fig. 5 Response thresholds of IC neurons to broadband noise $(B B N)$ and tone stimulation for control or sound-exposed $\mathrm{BDNF}^{P a x 2}$ wild-type $(W T c$, WTat $)$ and $\mathrm{BDNF}^{\text {Pax } 2}$ knockout $(K O c$, KOat $)$ animals. a Averaged thresholds of responses to $\mathrm{BBN}$ stimulation. $\mathbf{b}$ Box and whisker plot for thresholds of tone-evoked responses for neurons of individual $\mathrm{CF}$ frequency ranges $(4-9,10-15,16-30 \mathrm{kHz})$. c Scatter plots of pure tone thresholds as a function of neuronal $\mathrm{CF}$, shown separately for $\mathrm{BDNF}^{\text {Pax2 }}$ WT (WTc, $n=4$; WTat, $n=5$ ) and $\mathrm{BDNF}^{\text {Pax } 2}-\mathrm{KO}(\mathrm{KOc}, n=4$; KOat, $n=5)$ animals. d, e Parameters of the rate-intensity function (RIF) of responses

CF (Fig. 6a, middle CF, WTat: Mdn=10.7; KOat: $M d n=8.5$, ${ }^{* * *} p<0.001$; high CF, WTat: $\mathrm{Mdn}=9.8$; KOat: $\mathrm{Mdn}=7.9$, $* * * * p<0.0001)$. This indicates that after the onset of hearing, BDNF improves the short latency responses of IC neurons to sound. Only when these responses have been developed, such as in $\mathrm{BDNF}^{\text {Pax2 }}$-WT mice, this faster response behavior can be lost after traumatizing noise in the mature system.

The quality factor $Q_{10}$ of sound responses of IC neurons, which is reciprocally related to the excitatory area bandwidth $10 \mathrm{~dB}$ above threshold (the higher the $Q_{10}$, the sharper the tuning), may help to identify the type of neuron which responds to BDNF in the IC. $Q_{10}$ did not significantly differ between $\mathrm{BDNF}^{\operatorname{Pax}^{2}}-\mathrm{WTc}$ and $\mathrm{BDNF}^{\operatorname{Pax}_{2}}$-KOc mice over all $\mathrm{CF}$ ranges (Fig. 6b). to BBN stimulation for control or sound-exposed BDNF ${ }^{\text {Pax2 }}-\mathrm{WT}$ (WTc, WTat) and $\mathrm{BDNF}^{\text {Pax2 }}$-KO (KOc, KOat) animals. d Typical examples of RIFs for all groups of animals. e Average dynamic range, relative slope, and maximum response for all groups of mice. One-way ANOVA with Bonferroni's post hoc test and Kruskal-Wallis test with Dunn's multiple comparison test, n.s. $p>0.05, * p<0.05, * * p<0.01, * * * p<0.001$, $* * * * p<0.0001$. Data are presented as mean $\pm \mathrm{SD}$ or median with interquartile range and extremes. The numbers in the graphs indicate the numbers of neurons

However, after AT, $Q_{10}$ in neurons with middle and high $\mathrm{CF}$ in $\mathrm{BDNF}^{\text {Pax }^{2}}$-WTat mice was significantly more reduced than in $\mathrm{BDNF}^{\operatorname{Pax}^{2}}-\mathrm{KO}$ at animals (Fig. 6b, n.s. $p>0.05, * * p<0.01, * * * * p<0.0001$ ). Differences in peak $Q_{10}$ values in scatter plots categorized for frequency bands in control and KO animals (Fig. 6c, d) prompted us to investigate individual $Q_{10}$ values. Interestingly, in $\mathrm{CF}$ regions $>10 \mathrm{kHz}$, the number of IC neurons with $Q_{10}$ values $>4$ was significantly lower in sham-exposed $\mathrm{BDNF}^{\text {Pax2 }}-\mathrm{KO}$ than in shamexposed $\mathrm{BDNF}^{\text {Pax }_{2}}-\mathrm{WT}$ animals (Fig. 6e, $* p<0.05$, $\left.*^{*} p<0.01\right)$. This indicates that after the onset of hearing, BDNF in lower brain parts sharpens a very narrow tuning characteristic of IC neurons. Only when this 


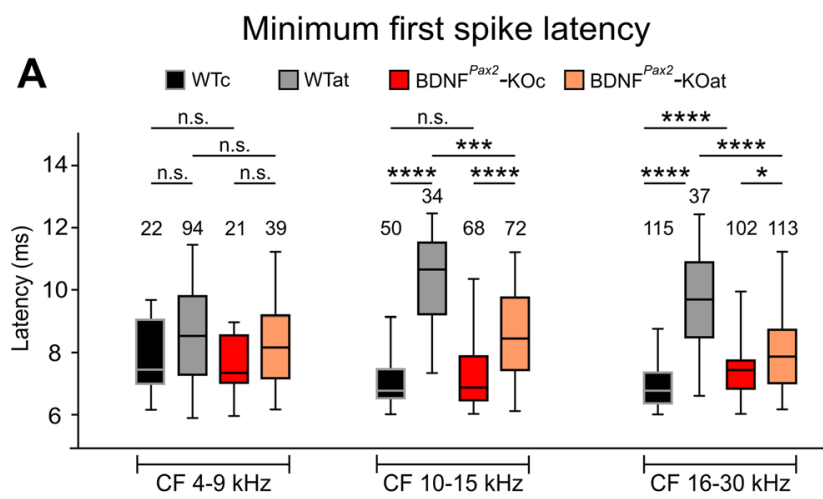

4 Fig. 6 Minimum first spike latency (mFSL) and quality factor $\left(Q_{10}\right)$ of IC neurons. a mFSL of responses to $80 \mathrm{~dB}$ SPL BBN bursts for control and sound-exposed BDNF ${ }^{\text {Pax } 2}$-WT (WTc, $n=4$; WTat, $\left.n=5\right)$ and

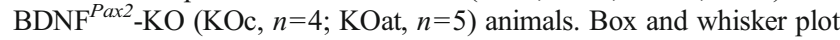
for $\mathrm{mFSL}$ for neurons of individual $\mathrm{CF}$ frequency ranges $(4-9,10-15$, $16-30 \mathrm{kHz}$ ). Kruskal-Wallis test with Dunn's post hoc test: n.s. $p>0.05$, ${ }^{*} p<0.05, * * * p<0.001, * * * * p<0.0001$. Data are presented as medians with interquartile ranges and extremes. b-e $Q_{10}$ of IC neuron responses to pure tone stimulation for control and sound-exposed $\mathrm{BDNF}^{\text {Pax2 }}$-WT (WTc, $n=4$; WTat, $n=5$ ) and $\mathrm{BDNF}^{\text {Pax }^{2}}$-KO (KOc, $n=4$; KOat, $n=5$ ) animals. b Box and whisker plot for $Q_{10}$ for neurons of individual $\mathrm{CF}$ frequency ranges $(4-9,10-15,16-30 \mathrm{kHz})$. c Scatter plots illustrating the $Q_{10}$ as a function of neuronal CF, shown separately for $\mathrm{BDNF}^{\operatorname{Pax} 2}-\mathrm{WT}$ and $\mathrm{BDNF}^{\operatorname{Pax}^{2}}-\mathrm{KO}$ animals. d, e Scatter plots for $Q_{10}$ with $y$ scale $0-8$ (d) and scale 4-8 (e) for the neurons of individual frequency ranges $(4-9,10$ $15,16-30 \mathrm{kHz}$ ). Note that IC neurons $>10 \mathrm{kHz}$ with $Q_{10}>5$ are absent in $\mathrm{BDNF}^{\operatorname{Pax}^{2}}$-KO mice (e). Kruskal-Wallis test with Dunn's multiple comparison test: n.s. $p>0.05, * * p<0.01, * * * * p<0.0001$. Data are presented as medians with interquartile ranges and extremes. The numbers in the graphs indicate the numbers of neurons

noise exposure, there was a likewise drop in the number of neurons displaying lateral inhibition in both groups of animals (data not shown).

Next, the strength of firing rate suppression by lateral

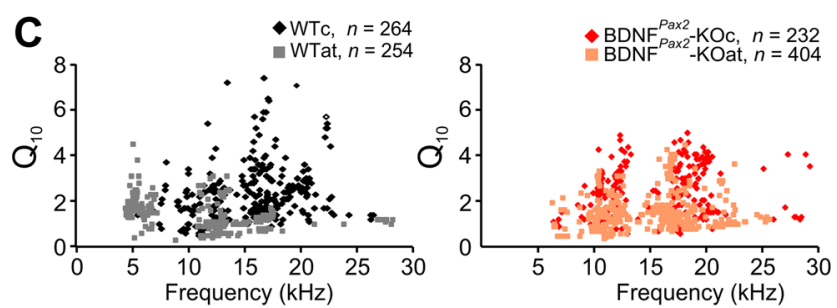
inhibition was calculated as a percentage of rate suppression separately for low- and high-frequency sideband inhibition for neurons with a $\mathrm{CF}<10 \mathrm{kHz}$ and $\mathrm{CF}>10 \mathrm{kHz}$. Low CF neurons did not exhibit altered low- or highfrequency sideband inhibitory strengths in the absence of BDNF or after AT (Fig. 7b). Likewise, in the neurons with a $\mathrm{CF}$ of $11-30 \mathrm{kHz}$, the low-frequency sideband was similar in $\mathrm{BDNF}^{\operatorname{Pax}^{2}}-\mathrm{WT}$ and $\mathrm{BDNF}^{\operatorname{Pax}^{2}}-\mathrm{KO}$ animals (Fig. 7b). However, high-frequency sideband inhibition strength was significantly reduced in sham-exposed

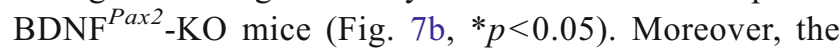
pronounced drop in the strength of high-frequency inhibition after AT observed in $\mathrm{BDNF}^{\text {Pax } 2}$-WT mice was not found in BDNFPax2 - KO animals (Fig. 7b, $* * * * p<0.0001)$. This indicates that after the onset of hearing, BDNF in lower brain parts increases the inhibitory strength of IC neuron that can be dropped after AT only when it has been increased before.

The stimulus-induced spike rates of IC neurons with middle and high $\mathrm{CF}$ in excitatory and noninhibitory regions were significantly elevated after $\mathrm{AT}$ in $\mathrm{BDNF}^{\text {Pax2 }}$ WT in comparison to $\mathrm{BDNF}^{\text {Pax2 }}$-KO mice (Fig. 7c). This is likely due to the drop in BDNF-driven inhibitory strength after AT in $\mathrm{BDNF}^{\text {Pax }^{2}}$-WT but not in $\mathrm{BDNF}^{\text {Pax2 }}$ KO mice (Fig. 7b). Importantly, these higher spike rates in

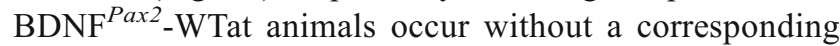
increase in sound-evoked spike output as revealed through a smaller ratio between spikes in excitatory and noninhibitory areas in $\mathrm{BDNF}^{\text {Pax }^{2}}$-WTat but not $\mathrm{BDNF}^{\text {Pax2 }}$ KOat mice (Fig. 7d). When the spontaneous firing rates of IC neurons from poststimulus histograms for BBN were 

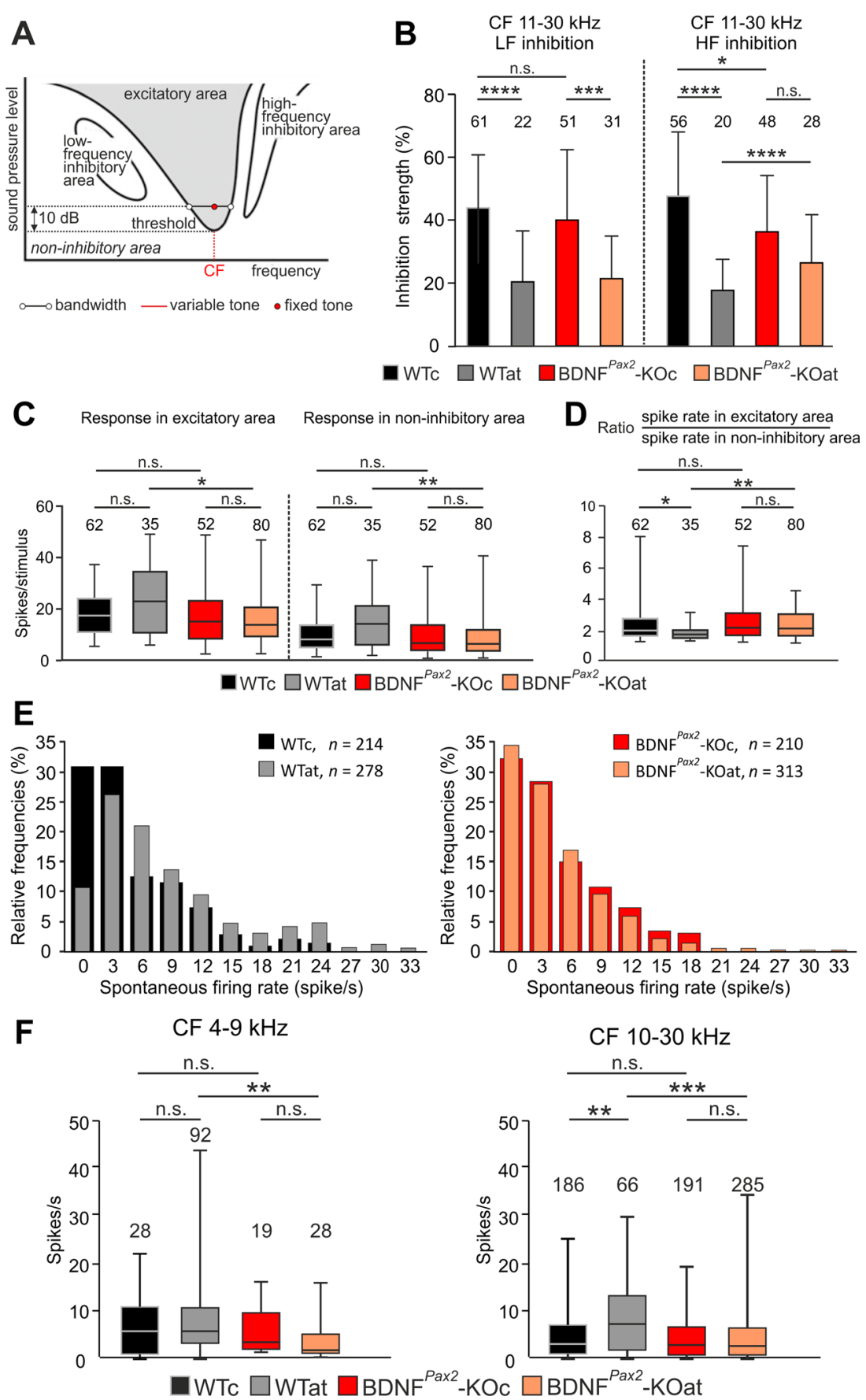

Fig. 7 Inhibition characteristics in control or sound-exposed $\mathrm{BDNF}^{\text {Pax2 }}$ WT (WTc, $n=4$; WTat, $n=5$ ) and $\mathrm{BDNF}^{\text {Pax } 2}-\mathrm{KO}$ (KOc, $n=4$; KOat, $n=5$ ) animals. a Schematic of response map to two-tone stimulation showing excitatory, inhibitory, and noninhibitory areas. b Comparison of low- and high-frequency sideband inhibition strength in middle and high CF (11$30 \mathrm{kHz}$ ) IC neurons with inhibitory strength of $1 \%$ and higher. One-way ANOVA with Bonferroni's post hoc test. $\mathbf{c}$ Spike rates of IC neurons with middle and high $\mathrm{CF}$ in response to two-tone stimulation, determined $20 \mathrm{~dB}$ above threshold in the excitatory area and noninhibitory area. Numbers in the graph indicate number of neurons. d Ratio of spike rates in the excitatory field $20 \mathrm{~dB}$ above threshold to spike rates in the noninhibitory area. The numbers of neurons are given above the corresponding boxes. Kruskal-Wallis test with Dunn's multiple comparison test: n.s. $p>0.05,{ }^{*} p<0.05, * * * p<0.001,{ }^{* * * *} p<0.0001$. Data are presented as mean $\pm \mathrm{SD}$ or median with interquartile range and extremes. e Distribution of IC neurons according to their spontaneous firing rate (spikes/s) for control and sound-exposed $\mathrm{BDNF}^{\text {Pax }}-\mathrm{WT}$ (WTc, $n=4$; WTat, $n=5$ ) and $\mathrm{BDNF}^{\text {Pax2 }}-\mathrm{KO}$ (KOc, $n=4$; KOat, $\left.n=5\right)$ animals. f Spontaneous firing rates for neurons with $\mathrm{CF}$ in the highfrequency band $(10-30 \mathrm{kHz})$ were significantly higher in $\mathrm{BDNF}^{\text {Pax }}$ WTat than in $\mathrm{BDNF}^{\text {Pax }}$-WTc but were similar in $\mathrm{BDNF}^{\text {Pax }}$-KOat and

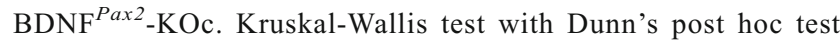
demonstrated significant differences between WTc and WTat $(* * p<0.01)$ and WTat and KOat $(* * * p<0.001)$ groups of animals. Data are presented as mean $\pm \mathrm{SD}$ or median with interquartile range and extremes. The numbers in the graphs indicate the numbers of neurons 
assessed after AT in $\mathrm{BDNF}^{\text {Pax2 }}$-WT mice (Fig. 7e), there was a significant drop in the proportion of neurons with a spontaneous firing rate close to $0(0-3$ spikes/s) $(32 \%$ for WT to $61 \%$ for KO, $\left.{ }^{* * *} p<0.001\right)$ and a shift of the distribution toward neurons with a higher spontaneous activity compared to $\mathrm{BDNF}^{P a x 2}-\mathrm{KO}$ at animals (WT: $\mathrm{Mdn}=3.8$ to $\mathrm{Mdn}=7.13,{ }^{* *} p<0.01$; KO: $\mathrm{Mdn}=4.13$ to $\mathrm{Mdn}=2.8$, n.s. $p>0.5$ ). These results underscore the loss of suppression of a BDNF-dependent firing rate. When spontaneous firing rates for low, middle, and high $\mathrm{CF}$ regions were analyzed separately, a significantly enhanced spontaneous firing rate for a $\mathrm{CF}>10 \mathrm{kHz}$ after $\mathrm{AT}$ in $\mathrm{BDNF}^{\text {Paxz }}$-WT but not in $\mathrm{BDNF}^{\text {Pax2 }}$-KO mice was observed (Fig. 7f). This finding strengthens the conclusion that BDNF may improve signal-to-noise ratio by increasing the inhibitory strength of neurons under basal conditions.

\section{Deletion of BDNF in BDNF ${ }^{P a x 2}$-KO but not $\mathrm{BDNF}^{\text {TrkC }}$-KO Mice Reduces the Density of PV-Immunopositive Puncta in IC and AC Projecting Neurons}

In many projection neurons, changes in inhibitory conductances are assumed to require specialized GABA $(\gamma-$ aminobutyric acid $)_{\mathrm{A}}$ receptors. Particularly, the differentiation of PV basket cells, a subpopulation of GABAergic neurons that regulate a critical period of plasticity in the cortex which depends on BDNF (for a review, see [54]), may play a role during the alteration of inhibitory strength in $\mathrm{BDNF}^{P a x 2}$-KOs. Likewise, elevated auditory startle amplitude and latencies in $\mathrm{PV}^{-/}$mice suggested a specific role of PV basket cells for inhibitory circuits in auditory processing [55]. To investigate a role of PV for the observed changes in inhibitory strength in $\mathrm{BDNF}^{\text {Pax } 2}-\mathrm{KO}$ mice, we used antibodies for PV $[56,57]$ and antibodies for the $67-\mathrm{kDa}$ isoform of GABAergic interneurons. We found that the intensity and number of PVimmunopositive puncta, but not the number of PVimmunopositive somata or GAD67-immunopositive puncta (not shown), are decreased in the IC and $\mathrm{AC}$ of $\mathrm{BDNF}^{\text {Pax2 }}$ KO (Fig. 8a, c) but not in BDNF ${ }^{\text {TrkC }}$-KO mice (Fig. 8b, d). Reduced levels of PV expression could also be confirmed by Western blots (Fig. 8a, b, inset). Quantification of the intensity of labeling revealed a significantly reduced number and intensity of PV-positive puncta (Fig. 8e, 10-20 slices of 3-6 independent experiments of $n=3$ animals) in $\mathrm{BDNF}^{\text {Pax2 }}-\mathrm{KO}$ mice. Also in the hippocampus, $\mathrm{PV}$ levels were reduced in $\mathrm{BDNF}^{\text {Pax2 }}$-KO but not in $\mathrm{BDNF}^{T r k C}-\mathrm{KO}$ mice, as exemplarily shown by Western blots (Fig. 8h). Interestingly, the reduction

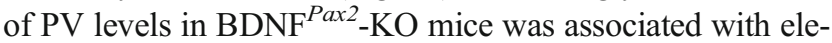
vated levels of the immediate early gene Arc (activity-regulated cytoskeletal protein), as exemplarily shown for the hippocampus (Fig. $8 \mathrm{~h}, n=3-5$ ). Arc is mobilized in glutamatergic neurons following, e.g., long-term potentiating (LTP)-like activity $[58,59]$. As $\mathrm{BDNF}^{\operatorname{Pax} 2}$-KO mice do not lack BDNF in the $\mathrm{AC}$ and hippocampus (Fig. 1c, e), future studies are required to investigate a potential developmental downregulation of Arc levels mediated by BDNF-dependent increases in inhibitory strength following onset of sensory function.

In conclusion and as outlined in Fig. 9, the data in the present study suggest that BDNF in the lower parts of the auditory system or within the cochlea (and not in the upper central auditory system) (Fig. 9 [1]) alters the afferent driving force for sound processing toward a wider dynamic range to which IC neurons can respond to sound intensities (Fig. 9 [2]). This is possibly mediated by generation and maintenance of increased inhibitory PV contacts with the auditory brain network that leads to enhanced spike probability in response to sensory stimulation. As shown for IC neurons, the BDNFmodified afferent driving force shortens response latency (Fig. 9 [3]) and lowers the CF detection threshold in IC neurons (Fig. 9 [4]) through the generation of a high-frequency inhibitory sideband (Fig. 9 [5]) in, e.g., very narrowly tuned IC neurons (Fig. 9 [6]). This suggests that the auditory driving force which depends on BDNF in the lower parts of the auditory CNS or within the cochlea may improve fidelity through enhancing the inhibitory strength within the auditory-specific network. When this driving force is lost after auditory nerve injury, such as following acoustic trauma, as shown here for traumatized BDNF ${ }^{P a x 2}$-WT animals, the auditory-specific network may lose its normal signal-to-noise ratio within the affected frequency range.

\section{Discussion}

The present study supports the hypothesis that the maturation of auditory nerve activity depends on BDNF in the lower parts of the auditory CNS or within the cochlea and is required to improve the fidelity of sound-induced responses after the onset of hearing. Improved auditory fidelity under control of this BDNF-dependent process is most likely achieved through enhancement of basal inhibitory circuits in the ascending auditory pathway. In the mature auditory organ, this BDNF-dependent driving force can be lost during, e.g., cochlear injury, leading to an elevated spontaneous firing rate, independently of a corresponding increase in sensory-evoked spikes.

\section{Peripheral but not Central BDNF Drives Changes in Sound Processing}

We show here that BDNF present in the lower parts of the auditory CNS or the peripheral end organ improves the threshold for sound and the dynamic range of sound responses. In both $\mathrm{BDNF}^{\text {Pax2 }}$-KO [25] and BDNF ${ }^{T r k C}-\mathrm{KO}$ animals (present study), BDNF is deleted in SGNs and in the IC, suggesting 

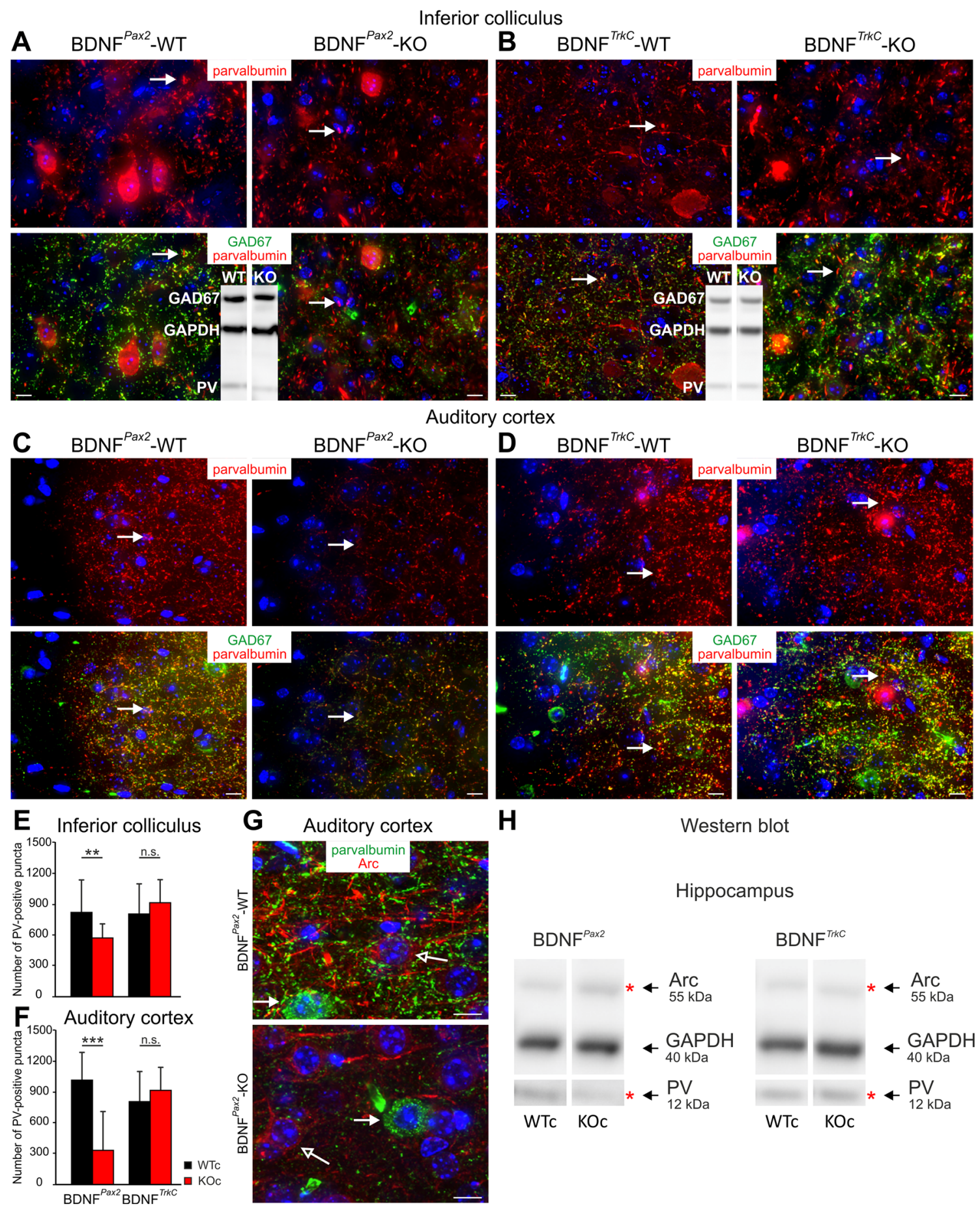

H

Western blot

Hippocampus

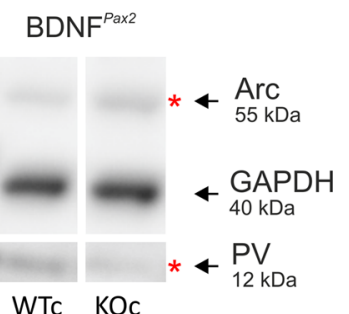

WTC KOC
$\mathrm{BDNF}^{\mathrm{T} \kappa \mathrm{C}}$

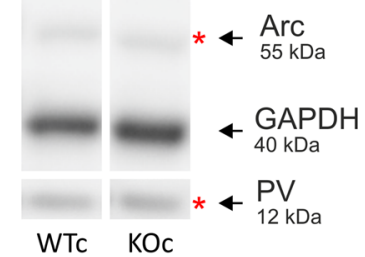

that alterations of BDNF activities in these compartments are unlikely to be responsible for the differences between soundinduced ABR wave I and IV responses in these mice. As

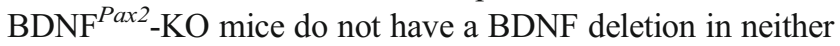
the AC, VCN, or olivary complex [present study] [25], descending central feedback loops are also unlikely to be involved. The observed hearing phenotype in $\mathrm{BDNF}^{\text {Pax } 2}-\mathrm{KO}$ mice may therefore be linked to a Pax2-driven BDNF deletion in the lower parts of the auditory CNS or the cochlea. In the cochlea, BDNF is expressed postnatally in phalangeal, SGN, or satellite cells $[22,25,50,60]$. Given that (i) BDNF deletion in phalangeal cells does not affect hearing thresholds [23], (ii) BDNF deletion in SGNs and in a minor number of supporting cells as observed in $\mathrm{BDNF}^{T r k C}-\mathrm{KO}$ mice does not lead to an auditory phenotype, and (iii) BDNF expression in inhibitory interneurons has been excluded $[52,61]$, the loss of BDNF expression in glial cells may be considered as being responsible for the observed phenotype in $\mathrm{BDNF}^{\text {Pax2 }}-\mathrm{KO}$ animals. 
4 Fig. 8 Immunohistochemistry of the inferior colliculus and auditory cortex of $\mathrm{BDNF}^{\operatorname{Pax}_{2}}-\mathrm{KO}$ and $\mathrm{BDNF}^{\text {TrkC }}-\mathrm{KO}$ mice. a-d Immunohistochemistry of the IC and $\mathrm{AC}$ of $\mathrm{BDNF}^{\text {Pax2 }}-\mathrm{KO}(\mathbf{a}, \mathbf{c})$ and $\mathrm{BDNF}^{T r k C}-\mathrm{KO}$ mice $(\mathbf{b}, \mathbf{d})$ immunolabeled with anti-parvalbumin $(\mathrm{red})$ and anti-GAD67 (green). A reduction of PV- and GAD67immunoreactive puncta in both IC (a) and $\mathrm{AC}(\mathbf{c})$ in $\mathrm{BDNF}^{\text {Pax2 }}-\mathrm{KO}$ mice compared to $\mathrm{BDNF}^{\text {Pax2 }}$-WT mice is observed. Arrows point to $\mathrm{PV}$-immunoreactive puncta. No changes in PV and GAD67 expression are observed in the IC $(\mathbf{b})$ and $\mathrm{AC}(\mathbf{d})$ of $\mathrm{BDNF}^{\text {TrkC }}$-KO mice compared to $\mathrm{BDNF}^{T r k C}$-WT mice. Arrows point to $\mathrm{PV}$-immunoreactive puncta. Reduced PV levels in $\mathrm{BDNF}^{\text {Pax }^{2}}-\mathrm{KO}$ but not $\mathrm{BDNF}^{\text {TrkC }}-\mathrm{KO}$ mice in the IC are confirmed by Western blot $(\mathbf{a}, \mathbf{b}$ insets). $\mathbf{e}, \mathbf{f}$ Quantification of $\mathrm{PV}$-immunoreactive puncta in the IC (e) of $\mathrm{BDNF}^{\text {Pax }}-\mathrm{WT}, \mathrm{BDNF}^{\text {Pax2 }}$ $\mathrm{KO}, \mathrm{BDNF}^{\text {TrkC}}-\mathrm{WT}$, and $\mathrm{BDNF}^{\text {TrkC}}-\mathrm{KO}$ mice (10-20 slices of 3-6 independent experiments of $n=3$ animals) and in the AC (f) of $\mathrm{BDNF}^{\text {Pax2 }}-\mathrm{WT}, \mathrm{BDNF}^{\text {Pax }}-\mathrm{KO}, \mathrm{BDNF}^{\text {TrkC }}-\mathrm{WT}$, and $\mathrm{BDNF}^{\text {TrkC }}-\mathrm{KO}$ mice (10-20 slices of 3-6 independent experiments of $n=3$ animals). Two-way ANOVA with Bonferroni's post hoc test $\left(* * p<0.01,{ }^{* * *} p<\right.$ 0.001 ). Data are presented as mean \pm SD. g Immunohistochemistry of $\mathrm{AC}$ sections of $\mathrm{BDNF}^{\text {Pax }^{2}}$-WT (upper image) and $\mathrm{BDNF}^{\text {Pax }} 2-\mathrm{KO}$ (lower image) mice immunolabeled with anti-Arc (red) and antiparvalbumin (green) antibodies. In $\mathrm{BDNF}^{\text {Pax2 }}$-KO mice, Arc (red) expression is reduced. Closed arrows point to PV-positive cells. Open arrows indicate $\mathrm{PV}$-immunoreactive puncta surrounding Arc-positive neurons. Scale bars $=10 \mu \mathrm{m}$. h Parvalbumin $(P V)$ and Arc levels in the hippocampus of BDNF ${ }^{\text {Pax }}-\mathrm{WT}$ and $\mathrm{BDNF}^{\text {Pax2 }}-\mathrm{KO}$ mice and $\mathrm{BDNF}^{\text {TrkC }}$ $\mathrm{WT}$ and $\mathrm{BDNF}^{T r k C}-\mathrm{KO}$ mice, respectively, detected by Western blots (exemplarily for $n=3-5$ mice). Note that the reduction of $\mathrm{PV}$ is associated to an increase of Arc in $\mathrm{BDNF}^{\text {Pax2 }}-\mathrm{KO}$ but not $\mathrm{BDNF}^{\text {TrkC }}$ KO mice

\section{Peripheral BDNF Improves Amplitudes of Spreading Sound-Induced Activity}

In our previous study, reduced exocytosis in otherwise mature IHCs in high-frequency cochlear turns of 2-3week-old $\mathrm{BDNF}^{\text {Pax } 2}-\mathrm{KO}$ mice [25] pointed out a critical role of BDNF for pre- and postsynaptic maturation of IHCs. The alterations in ABR waves I and IV found in the present study in $\mathrm{BDNF}^{\text {Pax }}-\mathrm{KO}$ but not $\mathrm{BDNF}^{\text {TrkC }}-\mathrm{KO}$ mice indicate that BDNF activities that are carried out independently of higher auditory brain regions improve sound sensitivity at least up to the level of the IC. We assume that in $\mathrm{BDNF}^{\text {Pax2 }}-\mathrm{KO}$ mice the decrease of $\mathrm{ABR}$ wave I and IV amplitude observed before AT and its reduced decline after AT occurs independently of the electromechanical properties of OHCs for the following reasons: (i) within the range of the stimulus levels in which ABR functions were quantified, no difference in DPOAEs, used as a measurement for mechanical properties of OHCs, was found; (ii) changes of suprathreshold responses after AT are seen in $\mathrm{BDNF}^{\text {Pax2 }}$-KO mice, but no differences are observed in DPOAE amplitudes after AT; and (iii) BDNF is not deleted in the olivocochlear brainstem nuclei that are projection fields of efferent fibers toward OHCs [25]. BDNF is therefore more likely to improve ABR amplitudes through its influence on IHC exocytosis and/or auditory fiber sensitivity for low sound thresholds. In this context, it is important to consider that low-threshold fiber characteristics develop only after hearing onset [62,63]. Also in the visual system, a role of retinal BDNF for improved retinal and visual acuity has been suggested [64]. Accordingly, an antisense-based inhibition of BDNF in the retina prevented an improvement of retinal stripe segregation induced by environmental enrichment as well as cortical acuity, even prior to eye opening $[16,17,64]$. To date, conditional deletion of retinal BDNF has not been performed, and it is therefore elusive if it improves the baseline of visual sensitivity independently of environmental enrichment, similar to the present findings.

\section{BDNF Drives Increased Inhibitory Strength Along the Auditory Pathway}

The current findings suggest that BDNF-dependent effects on auditory nerve activity are responsible not only for improving the ABR amplitude size of high-frequency sound responses spreading along the ascending pathway, but also for expanding the range of $\mathrm{CF}$ thresholds in these highfrequency $\mathrm{CF}$ regions. The affected $\mathrm{CF}$ regions $>10 \mathrm{kHz}$ span areas $(15-20 \mathrm{kHz})$ where murine behavioral auditory thresholds are at their lowest level [65]. We thus have to consider the improved CF thresholds, short latencies, and the increased strength of inhibitory sidebands of sharply tuned IC neurons

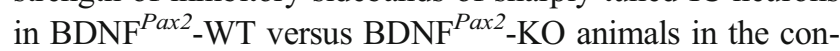
text of an enhanced auditory fidelity in behaviorally relevant frequency regions. The IC neurons that show altered tuning characteristics depending on the presence of BDNF are reminiscent of type II [65] and type I [66] class IC neurons. Both IC cell types predominate in high-frequency regions and are characterized by their short latency, narrow and sharp tuning, low-frequency border with a shallow slope, and highfrequency border with a steep slope [65, 66]. It thus may be considered that these neurons are shaped under the control of BDNF activities at hearing onset.

In $\mathrm{BDNF}^{\text {Pax2 }}-\mathrm{KO}$ animals, the proportion of neurons with an elevated spontaneous firing rate is slightly, however not yet significantly, increased. After AT, however, a significant drop in neurons with a lower spontaneous firing rate and an increase in neurons with a higher spontaneous firing rate in $\mathrm{BDNF}^{\text {Pax2 }}$-WT mice compared to $\mathrm{BDNF}^{\text {Pax }}$ KO animals support a loss of the BDNF-dependent rate of firing suppression after auditory nerve injury. Reminiscent to this finding, a reduced rate of firing suppression that leads to an increase of the spontaneous firing rate without a stimulus-evoked spike output was described after a blockade of tonic inhibition in granule cells of the cerebellar cortex [67]. It is currently assumed that tonic inhibition suppresses spontaneous activity through reduction of the neuronal input resistance and membrane time constants, 


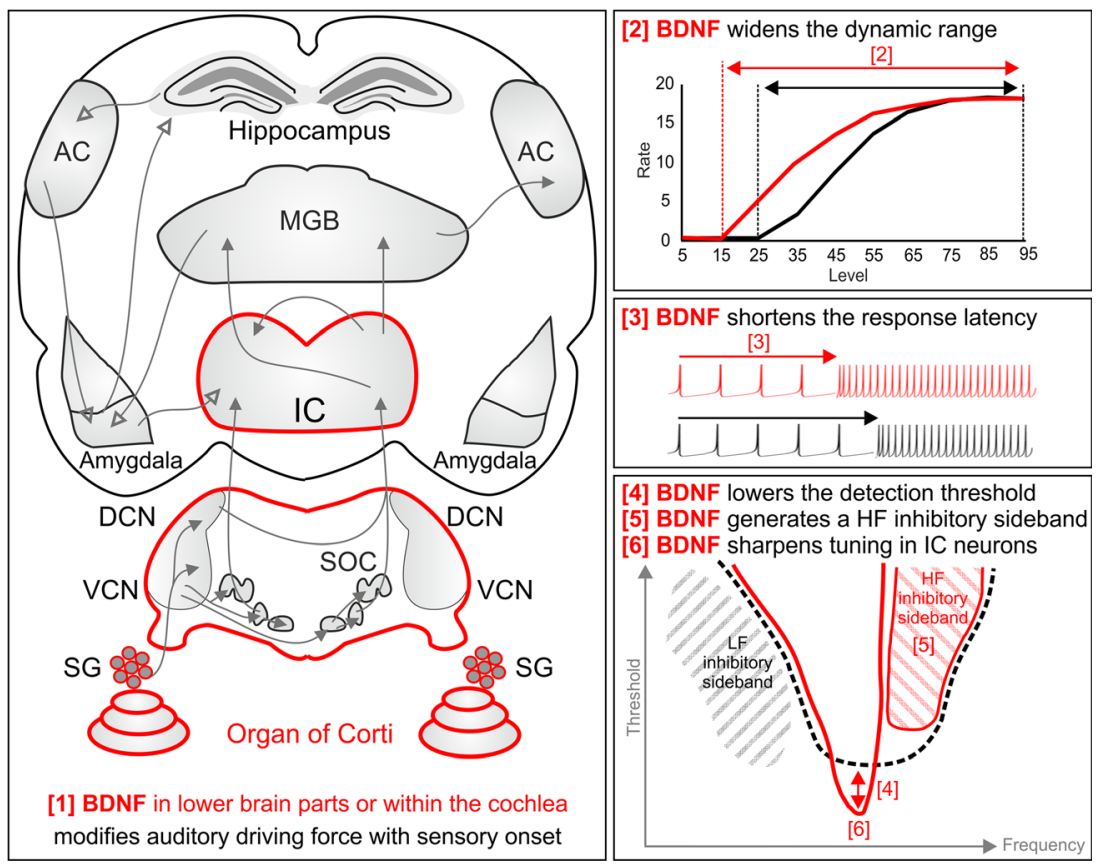

Fig. 9 Schematic summary of the results that illustrates our hypothesis. An auditory driving force which is modified with hearing onset and depends on BDNF in the lower parts of the auditory system or within the cochlea [1] widens the dynamic range above which spike rates can be detected [2]. This is achieved upon shortening of the response latency [3], leading to lowering of the detection threshold [4] through generation of a high-frequency inhibitory sideband [5] in, e.g., very narrowly tuned IC neurons [6]. Through these events, the probability to detect a spike above

thereby improving stimulus discrimination above noise [68]. The ability of tonic inhibition to change conductances in many neurons is assumed to require perisynaptic and extrasynaptic $\delta$ subunit-containing $\mathrm{GABA}_{\mathrm{A}}$ receptors, which are likely to be activated through fast-spiking, PVexpressing, and soma-inhibiting interneurons [69]. PVexpressing interneurons play a crucial role for hippocampal microcircuit formation and plasticity changes [70]. The significant loss of density of PV-immunopositive puncta in the IC and AC and the first evidence for declined PV levels associated with elevated Arc levels in the hippocampus of $\mathrm{BDNF}^{\text {Pax2 }}-\mathrm{KO}$ but not in $\mathrm{BDNF}^{\text {TrkC }}-\mathrm{KO}$ mice may suggest that a BDNF-modified driving force for auditory processing improves the baseline for mature circuit formation and plasticity changes along the entire ascending auditory network. This finding, moreover, suggests that the altered brain network activity shaped under the influence of BDNF in the lower parts of the auditory CNS or within the cochlea is a prerequisite for cortical maturation processes that occur with sensory experience [71-73]. The influence of dendritogenesis of PV-containing interneurons in the olfactory bulb [12], the auditory [8], visual [17, 74], and somatosensory cortex [11] on improved spectral and temporal cortical response properties [71-73] should be reconsidered in the context of these findings. the noise floor may be improved. This BDNF activity on auditory fibers in high-frequency cochlear turns can be lost after acoustic trauma. In this case, spontaneous spike rates in central auditory pathways are elevated (hyperactivity). As a consequence, due to loss of basal inhibitory strength within the ascending circuit of affected frequency regions, the capacity to adapt to sensory deprivation might be reduced. $H F$ high frequency, $I C$ inferior colliculus, $I H C$ inner hair cell, $L F$ low frequency

\section{Peripheral BDNF Improves Sound Fidelity but Carries the Risk to Enhance Central Noise Following Its Loss After Injury}

We observed here that suprathreshold ABR wave IV and CF threshold in IC neurons after AT were persistently more elevated in $\mathrm{BDNF}^{\text {Pax } 2}-\mathrm{WT}$ than in $\mathrm{BDNF}^{\text {Pax }}-\mathrm{KO}$ mice. This may be explained by a loss of auditory fiber characteristics that depend on BDNF and that are essential to maintain tonic inhibitory strength in the ascending pathways. As a result, spontaneous firing rates may be elevated within the affected frequency range without leading to sound-induced output as shown here in $\mathrm{BDNF}^{\mathrm{Pax} 2}$-WT but not in $\mathrm{BDNF}^{\mathrm{Pax} 2}$-KO mice.

A persistent reduction of suprathreshold amplitudes at the level of the IC has also been observed in traumatized rats with behaviorally tested tinnitus $[38,60]$ indicating that lost auditory nerve fiber activities that are typically maintained by BDNF in the lower parts of the auditory CNS or within the cochlea may be causally related to "phantom" noise. Previous observations that describe elevated intensity discrimination thresholds in tinnitus subjects with normal audiograms [75] may be re-examined in the context of a loss of signal-to-noise ratio in those frequency bands in which the BDNF-dependent driving force is lost. When the BDNF-dependent driving force is lost, the baseline levels required to allow the development 
of a normal adaptation of central brain responses after cochlear injury may be lost. In view of the current findings, a BDNFdependent auditory driving force may thus be the prerequisite for adaptive responses and central gain [76] after sensory deprivation $[74,77,78]$. Central maladaptive hyperactivities in various brain disorders including pain, Alzheimer, or epilepsy [79-81] and their enigmatic relationship to BDNF may be revisited in the context of the current findings [20, 21, 80]. For these disorders, a critical loss of the BDNF-dependent driving force should be taken into account.

Acknowledgments This work was supported by the Marie Curie Research Training Network CavNET MRTN-CT-2006-035367, the Deutsche Forschungsgemeinschaft DFG-Kni-316-4-1, and the Hahn Stiftung (Index AG)

\section{Compliance with Ethical Standards}

Conflict of Interest The authors declare that they have no competing interests.

Open Access This article is distributed under the terms of the Creative Commons Attribution 4.0 International License (http:// creativecommons.org/licenses/by/4.0/), which permits unrestricted use, distribution, and reproduction in any medium, provided you give appropriate credit to the original author(s) and the source, provide a link to the Creative Commons license, and indicate if changes were made.

\section{References}

1. Poo MM (2001) Neurotrophins as synaptic modulators. Nat Rev Neurosci 2:24-32

2. Barde YA (1990) The nerve growth factor family. Prog Growth Factor Res 2:237-248

3. Rauskolb S, Zagrebelsky M, Dreznjak A, Deogracias R, Matsumoto T, Wiese S, Erne B, Sendtner M, Schaeren-Wiemers N, Korte M et al (2010) Global deprivation of brain-derived neurotrophic factor in the CNS reveals an area-specific requirement for dendritic growth. J Neurosci 30:1739-1749

4. Bramham CR, Panja D (2014) BDNF regulation of synaptic structure, function, and plasticity. Neuropharmacology 76 Pt C:601-602

5. Maffei A, Lambo ME, Turrigiano GG (2010) Critical period for inhibitory plasticity in rodent binocular V1. J Neurosci 30:3304-3309

6. Maffei A, Turrigiano G (2008) The age of plasticity: developmental regulation of synaptic plasticity in neocortical microcircuits. Prog Brain Res 169:211-223

7. Kellner Y, Godecke N, Dierkes T, Thieme N, Zagrebelsky M, Korte M (2014) The BDNF effects on dendritic spines of mature hippocampal neurons depend on neuronal activity. Front Synaptic Neurosci 6:5

8. Xu H, Kotak VC, Sanes DH (2010) Normal hearing is required for the emergence of long-lasting inhibitory potentiation in cortex. $\mathrm{J}$ Neurosci 30:331-341

9. Kotak VC, Pendola LM, Rodriguez-Contreras A (2012) Spontaneous activity in the developing gerbil auditory cortex in vivo involves GABAergic transmission. Neuroscience 226:130-144

10. Gao M, Maynard KR, Chokshi V, Song L, Jacobs C, Wang H, Tran $\mathrm{T}$, Martinowich K, Lee HK (2014) Rebound potentiation of inhibition in juvenile visual cortex requires vision-induced BDNF expression. J Neurosci 34:10770-10779

11. Jiao Y, Zhang Z, Zhang C, Wang X, Sakata K, Lu B, Sun QQ (2011) A key mechanism underlying sensory experience-dependent maturation of neocortical GABAergic circuits in vivo. Proc Natl Acad Sci U S A 108:12131-12136

12. Berghuis P, Agerman K, Dobszay MB, Minichiello L, Harkany T, Ernfors P (2006) Brain-derived neurotrophic factor selectively regulates dendritogenesis of parvalbumin-containing interneurons in the main olfactory bulb through the PLCg pathway. J Neurobiol 66:1437-1451

13. Griffen TC, Maffei A (2014) GABAergic synapses: their plasticity and role in sensory cortex. Front Cell Neurosci 8:91

14. Vogels TP, Froemke RC, Doyon N, Gilson M, Haas JS, Liu R, Maffei A, Miller P, Wierenga CJ, Woodin MA et al (2013) Inhibitory synaptic plasticity: spike timing-dependence and putative network function. Front Neural Circ 7:119

15. Singer W, Panford-Walsh R, Knipper M (2014) The function of BDNF in the adult auditory system. Neuropharmacology $76 \mathrm{Pt}$ C:719-728

16. Landi S, Cenni MC, Maffei L, Berardi N (2007) Environmental enrichment effects on development of retinal ganglion cell dendritic stratification require retinal BDNF. PLoS One 2:e346

17. Landi S, Sale A, Berardi N, Viegi A, Maffei L, Cenni MC (2007) Retinal functional development is sensitive to environmental enrichment: a role for BDNF. FASEB J 21:130-139

18. Ernfors P, Lee KF, Jaenisch R (1994) Mice lacking brain-derived neurotrophic factor develop with sensory deficits. Nature 368:147-150

19. Jones KR, Farinas I, Backus C, Reichardt LF (1994) Targeted disruption of the BDNF gene perturbs brain and sensory neuron development but not motor neuron development. Cell 76:989-999

20. Lu B, Nagappan G, Guan X, Nathan PJ, Wren P (2013) BDNFbased synaptic repair as a disease-modifying strategy for neurodegenerative diseases. Nat Rev Neurosci 14:401-416

21. Lu B, Nagappan G, Lu Y (2014) BDNF and synaptic plasticity, cognitive function, and dysfunction. Handb Exp Pharmacol 220: 223-250

22. Sobkowicz HM, August BK, Slapnick SM (2002) Influence of neurotrophins on the synaptogenesis of inner hair cells in the deaf Bronx waltzer (bv) mouse organ of Corti in culture. Int J Dev Neurosci 20:537-554

23. Wan G, Gomez-Casati ME, Gigliello AR, Liberman MC, Corfas G (2014) Neurotrophin-3 regulates ribbon synapse density in the cochlea and induces synapse regeneration after acoustic trauma. Elife 3

24. Ohyama T, Groves AK (2004) Generation of Pax2-Cre mice by modification of a Pax2 bacterial artificial chromosome. Genesis 38:195-199

25. Zuccotti A, Kuhn S, Johnson SL, Franz C, Singer W, Hecker D, Geisler HS, Köpschall I, Rohbock K, Gutsche K et al (2012) Lack of brain-derived neurotrophic factor hampers inner hair cell synapse physiology, but protects against noise-induced hearing loss. J Neurosci 32:8545-8553

26. Fünfschilling U, Ng YG, Zang K, Miyazaki J, Reichardt LF, Rice FL (2004) TrkC kinase expression in distinct subsets of cutaneous trigeminal innervation and nonneuronal cells. J Comp Neurol 480: $392-414$

27. Šuta D, Popelár J, Syka J (2008) Coding of communication calls in the subcortical and cortical structures of the auditory system. Physiol Res 57(Suppl 3):S149-S159

28. Malmierca MS (2003) The structure and physiology of the rat auditory system: an overview. Int Rev Neurobiol 56:147-211

29. Rios M, Fan G, Fekete C, Kelly J, Bates B, Kuehn R, Lechan RM, Jaenisch R (2001) Conditional deletion of brain-derived neurotrophic factor in the postnatal brain leads to obesity and hyperactivity. Mol Endocrinol 15:1748-1757

30. Tan J, Rüttiger L, Panford-Walsh R, Singer W, Schulze H, Kilian SB, Hadjab S, Zimmermann U, Köpschall I, Rohbock K et al (2007) Tinnitus behavior and hearing function correlate with the 
reciprocal expression patterns of BDNF and Arg3.1/arc in auditory neurons following acoustic trauma. Neuroscience 145:715-726

31. Knipper M, Zinn C, Maier H, Praetorius M, Rohbock K, Köpschall I, Zimmermann U (2000) Thyroid hormone deficiency before the onset of hearing causes irreversible damage to peripheral and central auditory systems. J Neurophysiol 83:3101-3112

32. Franklin KBJ, Paxinos G (2008) The mouse brain in stereotaxic coordinates. Academic, San Diego

33. Heidrych P, Zimmermann U, Kuhn S, Franz C, Engel J, Duncker SV, Hirt B, Pusch CM, Ruth P, Pfister M et al (2009) Otoferlin interacts with myosin VI: implications for maintenance of the basolateral synaptic structure of the inner hair cell. Hum Mol Genet 18:2779-2790

34. Engel J, Braig C, Rüttiger L, Kuhn S, Zimmermann U, Blin N, Sausbier M, Kalbacher H, Munkner S, Rohbock K et al (2006) Two classes of outer hair cells along the tonotopic axis of the cochlea. Neuroscience 143:837-849

35. Dehmelt L, Halpain S (2005) The MAP2/Tau family of microtubule-associated proteins. Genome Biol 6:204

36. Winter H, Braig C, Zimmermann U, Geisler HS, Franzer JT, Weber T, Ley M, Engel J, Knirsch M, Bauer K et al (2006) Thyroid hormone receptors $\mathrm{TRa} 1$ and $\mathrm{TRb}$ differentially regulate gene expression of Kcnq4 and prestin during final differentiation of outer hair cells. J Cell Sci 119:2975-2984

37. Heidrych P, Zimmermann U, Bress A, Pusch CM, Ruth P, Pfister M, Knipper M, Blin N (2008) Rab8b GTPase, a protein transport regulator, is an interacting partner of otoferlin, defective in a human autosomal recessive deafness form. Hum Mol Genet 17:3814-3821

38. Rüttiger L, Singer W, Panford-Walsh R, Matsumoto M, Lee SC, Zuccotti A, Zimmermann U, Jaumann M, Rohbock K, Xiong H et al (2013) The reduced cochlear output and the failure to adapt the central auditory response causes tinnitus in noise exposed rats. PLoS One 8:e57247

39. Burkard RF, Don M (2007) The auditory brainstem response. In: Burkard RF, Don M, Eggemond JJ (eds) Auditory evoked potentials: basic principles and clinical application. Lippincott Williams \& Wilkins, Baltimore, pp 229-250

40. Grécová J, Bureš Z, Popelář J, Suta D, Syka J (2009) Brief exposure of juvenile rats to noise impairs the development of the response properties of inferior colliculus neurons. Eur J Neurosci 29:1921-1930

41. Konrad-Martin DL, Rübsamen R, Dörrscheidt GJ, Rubel EW (1998) Development of single- and two-tone responses of anteroventral cochlear nucleus neurons in gerbil. Hear Res 121:35-52

42. Kopp-Scheinpflug C, Dehmel S, Dörrscheidt GJ, Rübsamen R (2002) Interaction of excitation and inhibition in anteroventral cochlear nucleus neurons that receive large endbulb synaptic endings. J Neurosci 22:11004-11018

43. Spirou GA, Davis KA, Nelken I, Young ED (1999) Spectral integration by type II interneurons in dorsal cochlear nucleus. J Neurophysiol 82:648-663

44. Egorova M, Ehret G, Vartanian I, Esser KH (2001) Frequency response areas of neurons in the mouse inferior colliculus. I. Threshold and tuning characteristics. Exp Brain Res 140:145-161

45. Lu Y, Jen PH (2001) GABAergic and glycinergic neural inhibition in excitatory frequency tuning of bat inferior collicular neurons. Exp Brain Res 141:331-339

46. Sugimoto S, Hosokawa Y, Horikawa J, Nasu M, Taniguchi I (2002) Spatial focusing of neuronal responses induced by asynchronous twotone stimuli in the guinea pig auditory cortex. Cereb Cortex 12:506-514

47. Bureš Z, Grécová J, Popelář J, Syka J (2010) Noise exposure during early development impairs the processing of sound intensity in adult rats. Eur J Neurosci 32:155-164

48. Babcock AA, Kuziel WA, Rivest S, Owens T (2003) Chemokine expression by glial cells directs leukocytes to sites of axonal injury in the CNS. J Neurosci 23:7922-7930

49. Rüttiger L, Sausbier M, Zimmermann U, Winter H, Braig C, Engel J, Knirsch M, Arntz C, Langer P, Hirt B et al (2004) Deletion of the
$\mathrm{Ca}^{2+}$-activated potassium (BK) a-subunit but not the BKb1-subunit leads to progressive hearing loss. Proc Natl Acad Sci U S A 101: 12922-12927

50. Schimmang T, Tan J, Müller M, Zimmermann U, Rohbock K, Köpschall I, Limberger A, Minichiello L, Knipper M (2003) Lack of BDNF and TrkB signalling in the postnatal cochlea leads to a spatial reshaping of innervation along the tonotopic axis and hearing loss. Development 130:4741-4750

51. Turrigiano G (2007) Homeostatic signaling: the positive side of negative feedback. Curr Opin Neurobiol 17:318-324

52. Leto K, Rolando C, Rossi F (2012) The genesis of cerebellar GABAergic neurons: fate potential and specification mechanisms. Front Neuroanat 6:6

53. Heil P, Neubauer H, Brown M, Irvine DR (2008) Towards a unifying basis of auditory thresholds: distributions of the first-spike latencies of auditory-nerve fibers. Hear Res 238:25-38

54. $\mathrm{Hu} \mathrm{H}$, Gan J, Jonas P (2014) Interneurons. Fast-spiking, parvalbumin ${ }^{+}$GABAergic interneurons: from cellular design to microcircuit function. Science 345:1255263

55. Popelár J, Rybalko N, Burianová J, Schwaller B, Syka J (2013) The effect of parvalbumin deficiency on the acoustic startle response and prepulse inhibition in mice. Neurosci Lett 553:216-220

56. Le Magueresse C, Monyer H (2013) GABAergic interneurons shape the functional maturation of the cortex. Neuron 77:388-405

57. Sale A, Berardi N, Spolidoro M, Baroncelli L, Maffei L (2010) GABAergic inhibition in visual cortical plasticity. Front Cell Neurosci 4

58. Bramham CR, Alme MN, Bittins M, Kuipers SD, Nair RR, Pai B, Panja D, Schubert M, Soule J, Tiron A et al (2010) The Arc of synaptic memory. Exp Brain Res 200:125-140

59. Panja D, Bramham CR (2014) BDNF mechanisms in late LTP formation: a synthesis and breakdown. Neuropharmacology $76 \mathrm{Pt}$ C:664-676

60. Singer W, Zuccotti A, Jaumann M, Lee SC, Panford-Walsh R, Xiong H, Zimmermann U, Franz C, Geisler HS, Köpschall I et al (2013) Noise-induced inner hair cell ribbon loss disturbs central arc mobilization: a novel molecular paradigm for understanding tinnitus. Mol Neurobiol 47:261-279

61. Heimel JA, van Versendaal D, Levelt CN (2011) The role of GABAergic inhibition in ocular dominance plasticity. Neural Plast 2011:Article ID 391763

62. Grant L, Yi E, Glowatzki E (2010) Two modes of release shape the postsynaptic response at the inner hair cell ribbon synapse. J Neurosci 30:4210-4220

63. Knipper M, Panford-Walsh R, Singer W, Rüttiger L, Zimmermann U (2015) Specific synaptopathies diversify brain responses and hearing disorders: you lose the gain from early life. Cell Tissue Res 361:77-93

64. Landi S, Ciucci F, Maffei L, Berardi N, Cenni MC (2009) Setting the pace for retinal development: environmental enrichment acts through insulin-like growth factor 1 and brain-derived neurotrophic factor. J Neurosci 29:10809-10819

65. Hage SR, Ehret G (2003) Mapping responses to frequency sweeps and tones in the inferior colliculus of house mice. Eur J Neurosci 18:2301-2312

66. Hernández O, Espinosa N, Perez-Gonzalez D, Malmierca MS (2005) The inferior colliculus of the rat: a quantitative analysis of monaural frequency response areas. Neuroscience 132:203-217

67. Duguid I, Branco T, London M, Chadderton P, Hausser M (2012) Tonic inhibition enhances fidelity of sensory information transmission in the cerebellar cortex. J Neurosci 32:11132-11143

68. Caraiscos VB, Elliott EM, You-Ten KE, Cheng VY, Belelli D, Newell JG, Jackson MF, Lambert JJ, Rosahl TW, Wafford KA et al (2004) Tonic inhibition in mouse hippocampal CA1 pyramidal neurons is mediated by a5 subunit-containing g-aminobutyric acid type A receptors. Proc Natl Acad Sci U S A 101:3662-3667 
69. Ferando I, Mody I (2015) In vitro gamma oscillations following partial and complete ablation of $d$ subunit-containing GABA receptors from parvalbumin interneurons. Neuropharmacology 88:91-98

70. Jonas P, Buzsaki G (2007) Neural inhibition. Scholarpedia 2(9): 3286

71. Carcea I, Froemke RC (2013) Cortical plasticity, excitatoryinhibitory balance, and sensory perception. Prog Brain Res 207: 65-90

72. Han YK, Köver H, Insanally MN, Semerdjian JH, Bao S (2007) Early experience impairs perceptual discrimination. Nat Neurosci 10:1191-1197

73. Kilgard MP, Pandya PK, Engineer ND, Moucha R (2002) Cortical network reorganization guided by sensory input features. Biol Cybern 87:333-343

74. Nahmani M, Turrigiano GG (2014) Adult cortical plasticity following injury: recapitulation of critical period mechanisms? Neuroscience 283:4-16

75. Epp B, Hots J, Verhey JL, Schaette R (2012) Increased intensity discrimination thresholds in tinnitus subjects with a normal audiogram. J Acoust Soc Am 132:EL196-EL201
76. Knipper M, Van Dijk P, Nunes I, Rüttiger L, Zimmermann U (2013) Advances in the neurobiology of hearing disorders: recent developments regarding the basis of tinnitus and hyperacusis. Prog Neurobiol 111:17-33

77. Mandolesi G, Menna E, Harauzov A, von Bartheld CS, Caleo M, Maffei L (2005) A role for retinal brain-derived neurotrophic factor in ocular dominance plasticity. Curr Biol 15:2119-2124

78. Anomal R, de Villers-Sidani E, Merzenich MM, Panizzutti R (2013) Manipulation of BDNF signaling modifies the experiencedependent plasticity induced by pure tone exposure during the critical period in the primary auditory cortex. PLoS One 8:e64208

79. Scharfman HE, Chao MV (2013) The entorhinal cortex and neurotrophin signaling in Alzheimer's disease and other disorders. Cogn Neurosci 4:123-135

80. Smith PA (2014) BDNF: no gain without pain? Neuroscience 283: $107-123$

81. Song JH, Yu JT, Tan L (2015) Brain-derived neurotrophic factor in Alzheimer's disease: risk, mechanisms, and therapy. Mol Neurobiol 52(3):1477-1493 